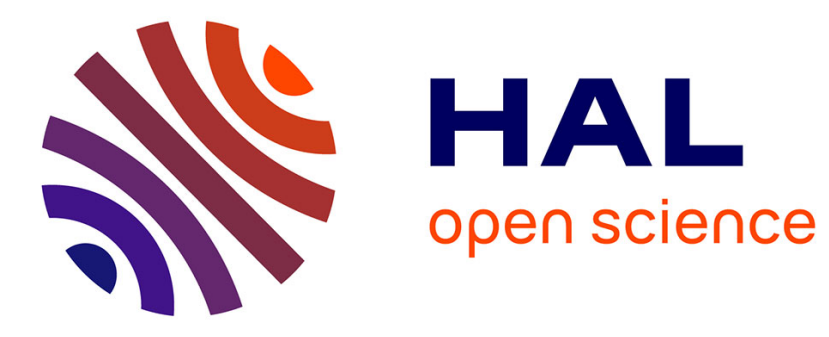

\title{
Molecular clips and tweezers hosting neutral guests
}

Marie Hardouin-Lerouge, Piétrick Hudhomme, Marc Sallé

\section{To cite this version:}

Marie Hardouin-Lerouge, Piétrick Hudhomme, Marc Sallé. Molecular clips and tweezers hosting neutral guests. Chemical Society Reviews, 2011, 40, pp.30-43. 10.1039/B915145C . hal-03344623

\section{HAL Id: hal-03344623 \\ https://univ-angers.hal.science/hal-03344623}

Submitted on 15 Sep 2021

HAL is a multi-disciplinary open access archive for the deposit and dissemination of scientific research documents, whether they are published or not. The documents may come from teaching and research institutions in France or abroad, or from public or private research centers.
L'archive ouverte pluridisciplinaire HAL, est destinée au dépôt et à la diffusion de documents scientifiques de niveau recherche, publiés ou non, émanant des établissements d'enseignement et de recherche français ou étrangers, des laboratoires publics ou privés. 
Cite this: Chem. Soc. Rev., 2011, 40, 30-43

\title{
Molecular clips and tweezers hosting neutral guests $\dagger$
}

\author{
Marie Hardouin-Lerouge, Piétrick Hudhomme* and Marc Sallé* \\ Received 17th May 2010 \\ DOI: $10.1039 / \mathrm{b} 915145 \mathrm{c}$
}

Intense current interest in supramolecular chemistry is devoted to the construction of molecular assemblies displaying controlled molecular motion associated to recognition. On this ground, molecular clips and tweezers have focused an increasing attention. This tutorial review points out the recent advances in the construction of always more sophisticated molecular clips and tweezers, illustrating their remarkably broad structural variety and focusing on their binding ability towards neutral guests. A particular attention is brought to recent findings in dynamic molecular tweezers whose recognition ability can be regulated by external stimuli. Porphyrin-based systems will not be covered here as this very active field has been recently reviewed.

\section{Introduction}

Supramolecular chemistry continues its expansion to include understanding and mimicking biological processes, molecular recognition, molecular self-assembly, catalysis, materials and medicinal chemistries, but also dynamic covalent chemistry. ${ }^{1}$ In particular, efforts were recently devoted to the synthesis of molecular machines that function through host-guest

Laboratoire MOLTECH-Anjou, Université d'Angers,

CNRS UMR 6200, 2 Boulevard Lavoisier, 49045 Angers, France.

E-mail: pietrick.hudhomme@univ-angers.fr,marc.salle@univ-angers.fr

$\dagger$ In memory of Professor Michel Jubault. recognition. Such systems are designed to achieve a specific function and considerable efforts are currently focused on the construction of molecular switches and devices in which external stimuli are used to induce molecular motion., ${ }^{2,3}$ Therefore, the design of molecular systems capable of controlled molecular-level motion has become an area of growing interest, and a key issue in this field concerns the so-called molecular tweezers, clips and clefts.

Such systems are characterized by open cavities capable of binding guests using various supramolecular interactions including hydrogen bonding, metal coordination, hydrophobic forces, van der Waals forces, electrostatic effects and/or $\pi-\pi$ interactions. Consequently, such molecular receptors are

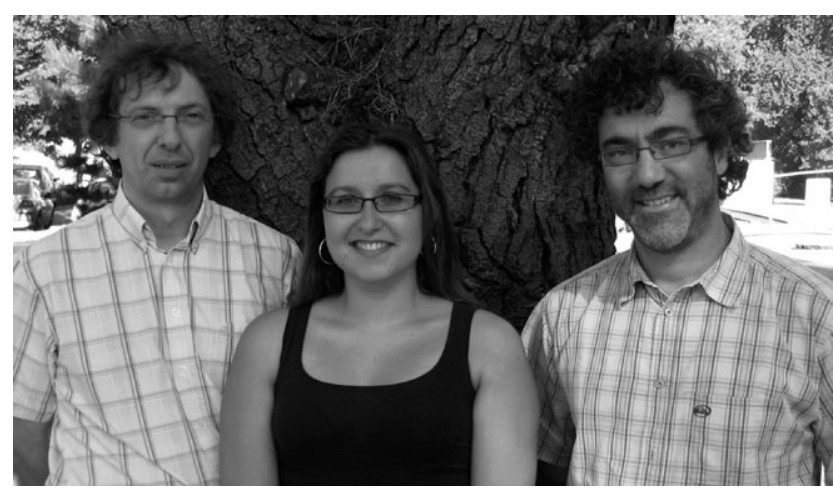

Piétrick Hudhomme, Marie Hardouin-Lerouge and Marc Sallé
Marie Hardouin-Lerouge received her Master Degree from the University of Angers in Molecular Engineering and Nanosciences in 2008. She is presently a PhD student in organic chemistry under the supervision of Prof. Piétrick Hudhomme. Her research interest is the synthesis and properties of electroactive molecular clips for supramolecular recognition.

Piétrick Hudhomme received his PhD from the University of Nantes in 1990 under the supervision of Prof. Guy Duguay for research on multi-step asymmetric synthesis of cephalosporin antibiotics. After post-doctoral research with Prof. Douglas W. Young (University of Sussex), he became Maitre de Conférences at the University of Nantes (1991). His research activities moved to the synthesis of organic materials and he was appointed Professor at the University of Angers (1998) in the laboratory of Prof. Alain Gorgues. His research interests encompass the organic synthesis of functional electroactive molecules for applications in molecular electronics, solar energy conversion and supramolecular chemistry.

Prof. Marc Sallé studied chemistry at the Ecole Nationale Supérieure de Chimie de Rennes (ENSCR) and at the University of Paris VI. He received his PhD in Organic Chemistry (University of Angers, 1991) with Prof. Alain Gorgues and received the Dina Surdin prize in 1992. After a postdoc with Prof. M. R. Bryce (University of Durham, UK), he became Maitre de Conférences at the University of Angers, and became Professor in 1998. He was elected as a junior member of the Institut Universitaire de France (IUF) in 2003. His research interests concern organic chemistry of molecular materials and supramolecular chemistry. 


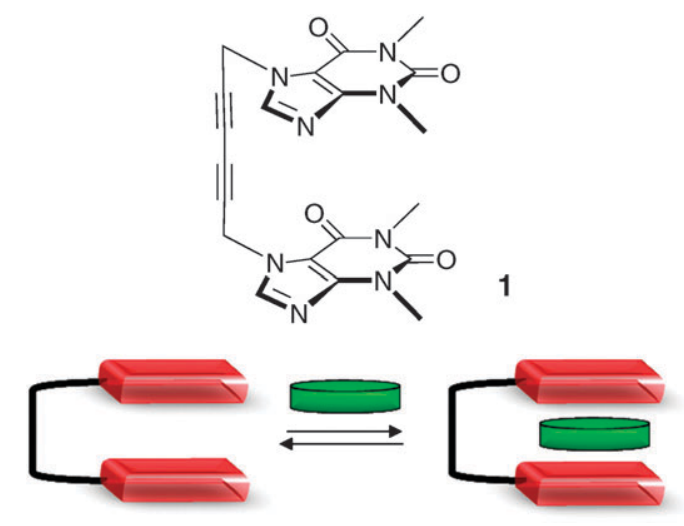

Fig. 1 First molecular tweezer described by Chen and Whitlock and its principle of supramolecular recognition.

designed with two 'arms' or 'tips' chosen for their propensity to sandwich a given guest, and which are connected through a central platform.

The term 'molecular tweezer' was introduced by Whitlock, ${ }^{4}$ defining a molecular receptor characterized by two flat, generally aromatic, identical pincers separated by some more or less rigid tether. Subsequently, some criteria were established to define a molecular tweezer. ${ }^{5,6}$ These are: (i) the presence of a spacer that prevents self-association, (ii) a spacer that establishes a distance of ca. $7 \AA$ between the pincers (plane to plane or centroid to centroid), suitable for the inclusion of a single aromatic guest molecule, and (iii) a spacer that holds the pincers rigidly in a syn conformation. In their original publication, Chen and Whitlock described the flexible molecular tweezer 1 involving two caffeine chromophores separated by a diyne spacer (Fig. 1).

Compound 1 can bind aromatic guests by sandwiching them between two more or less parallel aromatic side-walls. Since then, a large number of synthetic host systems based on this principle have been designed. Their structure potentially varies according to two parameters: (i) the chemical nature of the pincer, which is the active unit in terms of molecular recognition, and (ii) the nature of the connecting platform between both pincers, whose attribute is to fix the relative location of the latter.

F. G. Klärner et al. developed di- to tetramethylene-bridged compounds 2-4 and defined these systems as molecular clips and tweezers, respectively (Fig. 2). ${ }^{7}$ These architectures are characterized by "bond angle distortions which require little energy and, therefore, should induce a certain flexibility, allowing the receptor 'arms'to be expanded and compressed

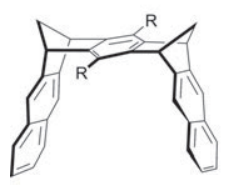

2

Molecular clip

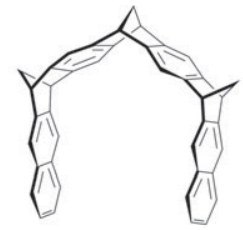

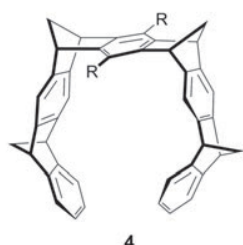

4

Molecular tweezer

Fig. 2 Molecular clip to molecular tweezer as defined by Klärner with di-, tri- and tetramethylene-bridged polyaromatic systems.

during the substrate complexation". Nevertheless, it is worth noting that although the concepts of molecular tweezers and molecular clips are sometimes considered separately, there seems to be relatively little to distinguish the two groups. Therefore, we have considered in this review, the so-called molecular clefts, clips, and tweezers at the same level.

Several reviews have already been published in the past on this subject, but they all focus on a specific aspect: Zimmerman in $1991^{8}$ and $1993^{5}$ on rigid molecular tweezers, Nolte in $1995^{9}$ and $1999^{10}$ on glycoluril-based molecular clips, Klärner in 2003 on polyarene molecular clips and tweezers, ${ }^{7}$ Harmata in 2004 on chiral molecular tweezers, ${ }^{6}$ and very recently, in 2010 , Martín on molecular tweezers specifically designed for fullerene binding. ${ }^{11}$ Therefore, no recent general review is available. At this stage, one should mention that given a remarkable combination of photo- and electrochemical properties, the aromatic porphyrin unit has focused a tremendous interest for the construction of tweezer-like architectures, through the preparation of covalently linked cofacial bisporphyrins. This very active field has been recently reviewed $^{12}$ and despite their interest, porphyrin-based systems will not be covered in the present tutorial review.

In this tutorial review, recent work on molecular tweezers, clips or clefts, organized around a rigidified platform and capable to form host-guest complexes with neutral molecules such as aromatic or fullerene guests by using $\pi-\pi$ stacked aromatic interactions will be presented. Are also considered in this review, dynamic molecular tweezers whose recognition ability can be regulated through large-scale open-close movement induced by different kind of stimuli. This class of synthetic receptors is emerging in the literature and recent examples involved in the binding of neutral guests will be presented.

\section{Rigid molecular clips}

\subsection{The glycoluril scaffold}

The popularity of glycoluril as a building block in supramolecular chemistry can be traced to the pioneering work on molecular clips of Nolte et al. who discovered that the reaction of diphenylglycoluril 5 with formaldehyde gave a clip-shaped molecule 6 with a rigid U-shaped cavity (Fig. 3)., ${ }^{9,10}$

The introduction of two phenyl rings afforded the clip-shaped molecule 7 (Fig. 4); a great variety of phenylglycoluril-based host derivatives possessing various functionalities has been synthesized from this platform. Consequently, diphenylglycoluril molecular clips were found to be attractive because of: (i) a straightforward synthetic access to a wide range of derivatives; (ii) a suitable preorganization of the aromatic binding sites for accommodating an aromatic moiety in the cleft.<smiles>CN1C(=O)NC2(c3ccccc3)NC(=O)NC12c1ccccc1</smiles>

5

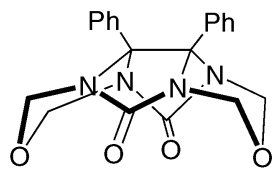

6
Fig. 3 Structure of the glycoluril scaffold 6 . 


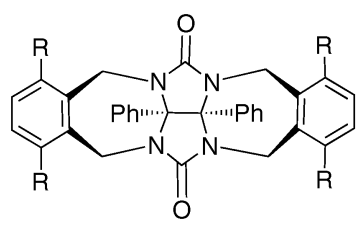

7 a : $\mathrm{R}=\mathrm{H}, \mathrm{b}: \mathrm{R}=\mathrm{Me}$, $c: R=O H, d: R=O M e$

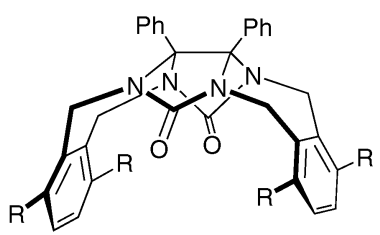

Fig. 4 General structure of glycoluril-based molecular clips.

The X-ray structure of the tetramethoxy derivative 7d shows that the $o$-xylylene walls define a cavity with an angle of $39.5^{\circ}$ between both aromatic walls and a distance of $6.67 \AA$ between the centers of the benzene rings. The two fused five-membered rings of glycoluril form an electron rich base, with two hydrogen bond acceptor sites. ${ }^{13}$ Complexation experiments showed that molecular clips 7 are good receptors for phenols, dihydroxybenzene or dihydroxynaphthalene derivatives. The binding process involves cooperative hydrogen bonding and $\pi-\pi$ stacking interactions and high binding constants are found $\left(K_{\mathrm{a}}=7100 \mathrm{M}^{-1}\right.$ in $\mathrm{CDCl}_{3}$ for clip $7 \mathbf{d}$ and 2,7-dihydroxynaphtalene). The binding ability appears very low with molecular clip 8 presenting 1,4-dimethoxynaphthalene tips. The corresponding X-ray crystal structure shows that all methoxy groups point into the cavity, preventing thus any complexation process (Fig. 5). On the other hand, when naphthalene walls are connected in the 1,8 positions, glycoluril 9 exists in solution as a mixture of three conformers which slowly interconvert on the NMR time scale. Only one conformer contains a cavity which can bind an aromatic guest $\left(K_{\mathrm{a}}=185 \mathrm{M}^{-1}\right.$ in $\mathrm{CDCl}_{3}$ for 1,4-dicyanobenzene). ${ }^{14}$
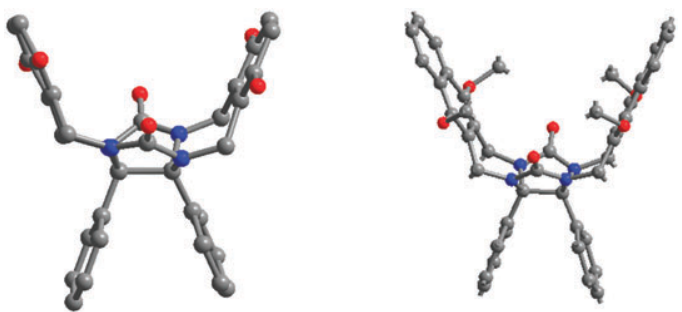

Fig. 5 X-Ray structures of diphenylglycoluril molecular clips 7d (left) and $\mathbf{8}$ (right).
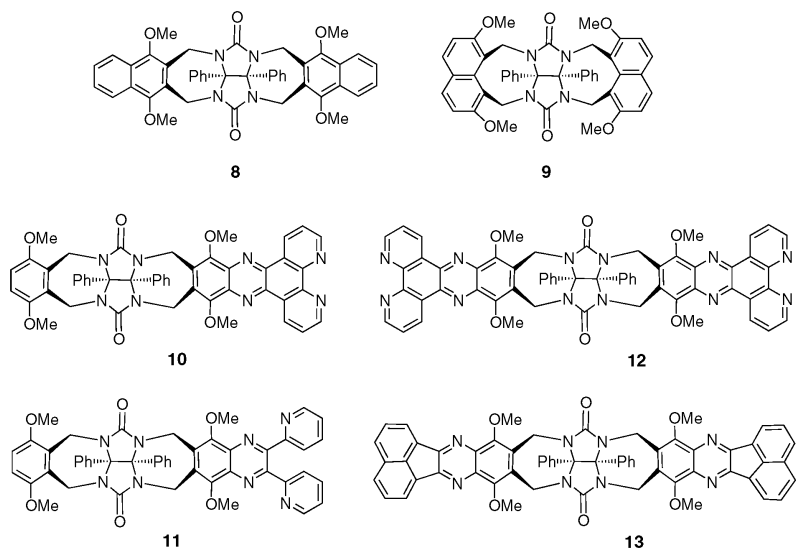

Fig. 6 Molecular clips based on the glycoluril scaffold.
Different types of sidewalls have been introduced in order to establish some structure-properties relationships (Fig. 6). For example, the monophenanthroline clip 10 and dipyridine clip 11 are able to complex olivetol (5-pentylresorcinol) with moderate binding constants $\left(K_{\mathrm{a}}=210 \mathrm{M}^{-1}\right.$ and $125 \mathrm{M}^{-1}$, respectively, $\mathrm{CDCl}_{3}$ ) whereas the diphenanthroline clip 12 does not present this host property $\left(K_{\mathrm{a}}<1 \mathrm{M}^{-1}\right) .{ }^{15}$ For this series, steric effects are considered to be unfavourable for high binding constants. This is also illustrated by the fact that simple molecular clip 7d shows a good affinity for olivetol $\left(K_{\mathrm{a}}=1500 \mathrm{M}^{-1}\right)$. On the other hand, the recently described glycoluril clip 13 containing arene-terminated sidewalls was recently shown to provide a deep cavity suitable for efficiently binding resorcinol. ${ }^{16}$

Recently, molecular clip $\mathbf{1 4}$ based on glycoluril scaffold in which both phenyl groups have been replaced by two ester functionalities was synthesized (Fig. 7). ${ }^{17}$ Two extended ethynylated $o$-xylylene sidewalls provide the formation of a deep cavity. The high sensitivity and low limit detection of fluorescence spectroscopy was used to demonstrate the highly selective recognition properties of this fluorescent molecular clip towards 4-nitrophenol $\left(K_{\mathrm{a}}=1.09 \times 10^{4} \mathrm{M}^{-1}\right.$ in $\mathrm{THF}-\mathrm{MeOH} 9: 1)$. Beside a cavity effect, this binding is driven by a combination of hydrogen bonding and $\pi-\pi$ stacking interactions between the electron-poor aromatic guest and the electron-rich sidewalls of the host, which induces a fluorescence quenching.

The ability of methylene-bridged glycoluril dimers $\mathbf{1 5}$ to undergo strong dimerization $\left(K_{\mathrm{a}}>10^{6} \mathrm{M}^{-1}\right.$ in $\left.\mathrm{CDCl}_{3}\right)$ was recently investigated to prepare robust, functionalizable, self-sorting supramolecular systems (Fig. 8). ${ }^{18}$ Such systems tend to self-organize in dimers resulting from the combination of hydrogen-bonds and $\pi-\pi$ interactions.
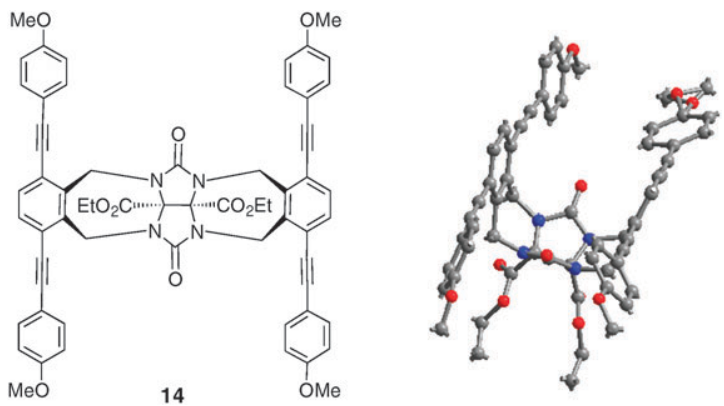

Fig. 7 Fluorescent glycoluril-based molecular clip $\mathbf{1 4}$ and X-ray crystal structure.
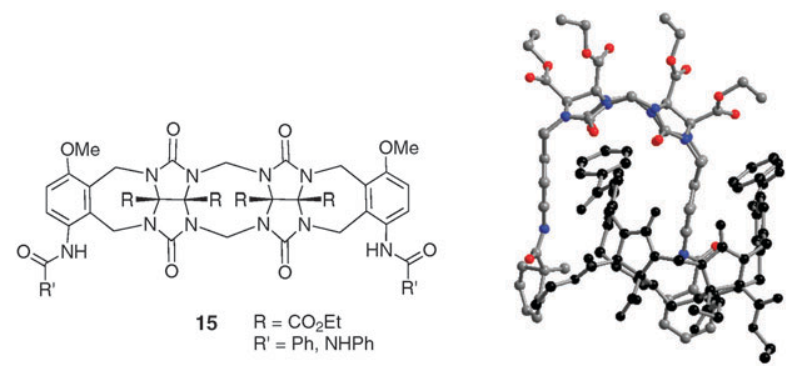

Fig. 8 Dimeric glycoluril molecular clip 15 and its self-association observed by X-ray study. 

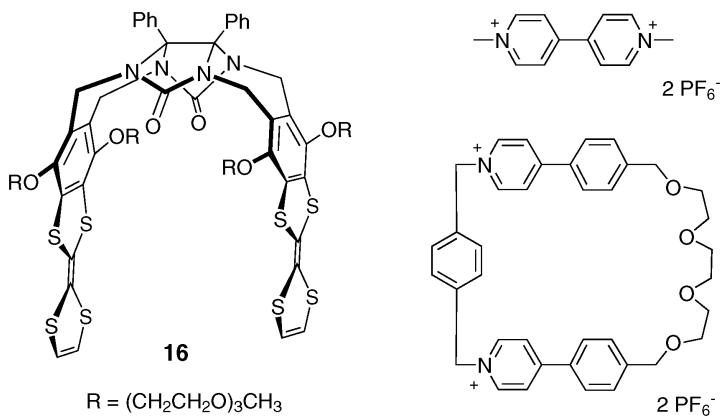

Fig. 9 Glycoluril-based molecular clip 16 with TTF sidewalls, and complementary bipyridinium guests.

One original feature of glycoluril-based molecular clips was recently described by Chiu and Coll. with the synthesis of compound 16, in which strong electron donor tetrathiafulvalene (TTF) units are introduced as sidewalls of the clip (Fig. 9). ${ }^{19,20}$ TTF units are located face-to-face at a suitable interplanar distance to allow the inclusion of guest species such as pyridinium motifs. Although this paraquat analogue is not a neutral molecule, this recent finding opens new development for glycolurile based molecular clips. Because of chargetransfer interactions and $\mathrm{C}-\mathrm{H} \cdots \mathrm{O}$ bonding, clip $\mathbf{1 6}$ was found to form complexes with paraquat $\left(K_{\mathrm{a}}=5600 \mathrm{M}^{-1}\right.$ in $\left.\mathrm{CD}_{3} \mathrm{CN}\right)$ or bipyridinium-based macrocycle $\left(K_{\mathrm{a}}=1600 \mathrm{M}^{-1}\right)$. The threaded and unthreaded states can be distinguished by their absorption spectra that correspond to a color change which can be readily seen by the naked eye. Interestingly, the exchange between threaded and unthreaded states can be controlled either by recognition of $\mathrm{K}^{+}$or $\mathrm{NH}_{4}{ }^{+}$, by heating

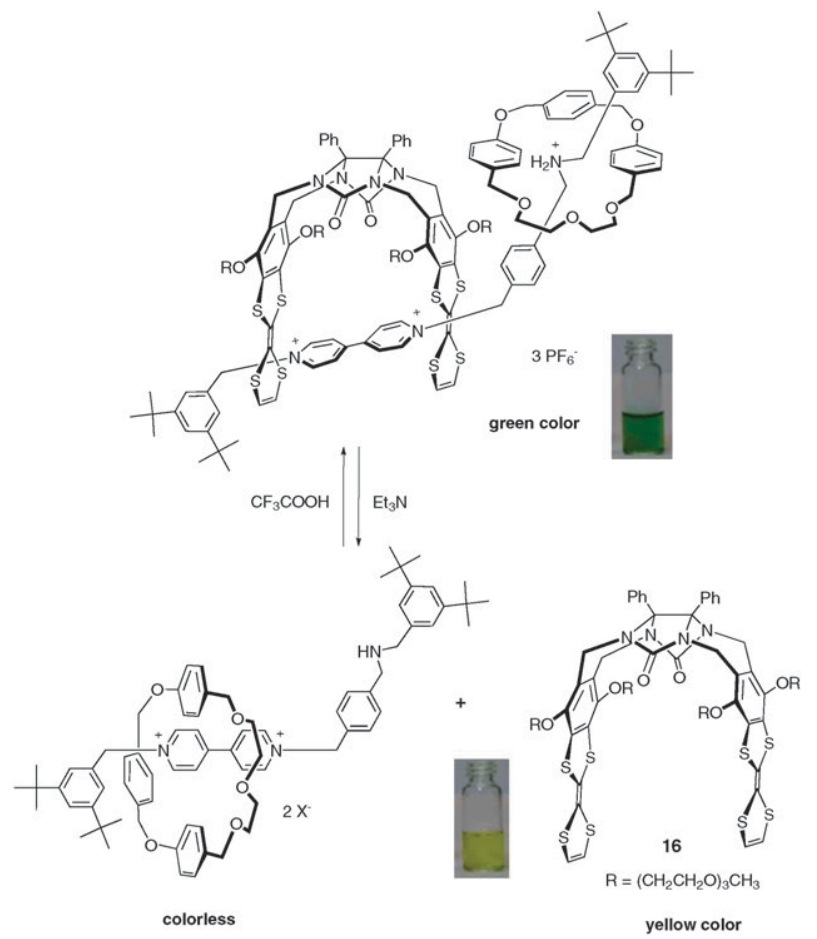

Fig. 10 Formation of the [2]rotaxane/clip 16 complex and corresponding $\mathrm{pH}$ controllable switching (reproduced with permission from ref. 21. Copyright Royal Society of Chemistry 2010). or by oxidation of the TTF moieties, which can lead to the dissociation of the macrocycle/molecular-clip complex. The latter complex operates as a "not-or" (NOR)-functioning molecular logic gate.

Molecular clip 16 can also operate in the presence of a twostation [2]rotaxane, as a pH-controllable molecular switch which can be monitored by naked eye. ${ }^{21}$ When solutions of colourless [2] rotaxane and yellow molecular clip $\mathbf{1 6}$ are mixed, the solution turns green because of a charge transfer band $(\lambda=709 \mathrm{~nm})$ resulting from the formation of [2]rotaxane/clip complex $\left(K_{\mathrm{a}}=4100 \mathrm{M}^{-1}\right.$ in $\left.\mathrm{CD}_{3} \mathrm{CN} / \mathrm{CDCl}_{3} 5: 1\right)$ (Fig. 10). This complex is dissociated by addition of $\mathrm{Et}_{3} \mathrm{~N}$ and can be reformed upon introduction of $\mathrm{CF}_{3} \mathrm{CO}_{2} \mathrm{H}$.

\subsection{Rigidified polyarene platforms}

Zimmerman and co-workers designed molecular tweezers presenting a high degree of pre-organization with a spacer that maintains a syn conformation of the binding arms. ${ }^{5}$ Representative examples are shown with compounds 17-19. Such systems exhibit a certain degree of conformational mobility since both pincers can potentially rotate around the bond connecting them to the central platform (Fig. 11). Such rotation changes the cavity size, allowing some optimization to take place upon inclusion of guest species.

In the dibenz $[c, h]$ acridine $\mathrm{U}$-shaped spacer, chromophores are attached at the $\mathrm{C}-2$ and $\mathrm{C}-12$ positions, which are separated by $7.24 \AA$. That is slightly larger than the $6.8 \AA$ interchromophore separation, which is optimum for sandwiching an aromatic guest. The tweezer exhibits conformational mobility and can readily adjust the size of this aromatic cleft for binding an aromatic guest. ${ }^{22}$ The two acridine units of such molecular tweezers show interesting cooperativity in sandwiching 2,4,7-trinitrofluorenone (TNF) guest for 17 $\left(\mathrm{R}, \mathrm{R}^{\prime \prime}=t \mathrm{Bu} ; \mathrm{R}^{\prime}=\mathrm{H}\right)\left(K_{\mathrm{a}}=172 \mathrm{M}^{-1} \text { in } \mathrm{CDCl}_{3}\right)^{23}$ and 2,4,5,7-tetranitrofluorenone (TENF) for $\mathbf{1 7}\left(\mathrm{R}, \mathrm{R}^{\prime}=\mathrm{OMe}\right.$; $\left.\mathrm{R}^{\prime \prime}=3,5-\mathrm{di}-t \mathrm{Bu}\right)\left(K_{\mathrm{a}}=3400 \mathrm{M}^{-1}\right) \cdot{ }^{24}$ The minor role played by the spacer was evidenced in that series and the affinity for TENF guest can be increased by substituting acridines with methoxy groups or replacing the acridine of tweezer 17 by one to two anthracene ring in tweezers 18 and 19 respectively $\left(K_{\mathrm{a}}=900 \mathrm{M}^{-1}\right.$ in $\mathrm{CDCl}_{3}$ for $\mathbf{1 7}, K_{\mathrm{a}}=2800 \mathrm{M}^{-1}$ for $\mathbf{1 8}$ and $K_{\mathrm{a}}=20000 \mathrm{M}^{-1}$ for 19). ${ }^{5}$ An extension of this tweezers family lies on the introduction of an active carboxylic acid site oriented toward the binding cleft, resulting in an increasing the $\mathrm{C}-2$ to $\mathrm{C}-12$ distance to $8.2 \AA$ (Fig. 12). A very high affinity was found for tweezer 20a $\left(K_{\mathrm{a}}=25000 \mathrm{M}^{-1}\right.$ in $\left.\mathrm{CDCl}_{3}\right)$ for

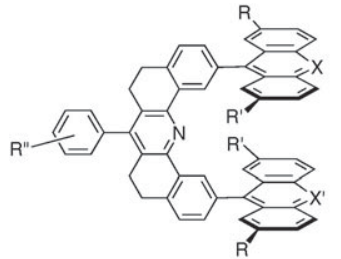

$17 \mathrm{X}=\mathrm{N}, \mathrm{X}^{\prime}=\mathrm{N}$ $18 \mathrm{X}=\mathrm{CH}, \mathrm{X}^{\prime}=\mathrm{N}$ $19 \mathrm{X}=\mathrm{CH}, \mathrm{X}^{\prime}=\mathrm{CH}$

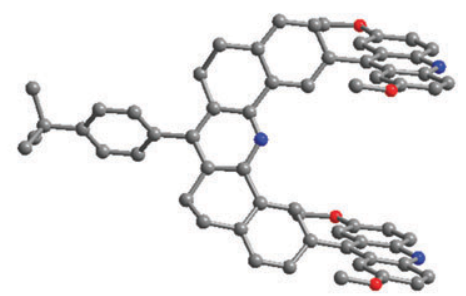

Fig. 11 Molecular tweezers containing a dibenz $[c, h]$ acridine U-shaped spacer; X-ray crystal structure of compound $17\left(\mathrm{R}, \mathrm{R}^{\prime}=\right.$ $\left.\mathrm{OMe}, \mathrm{R}^{\prime \prime}=4-t \mathrm{Bu}\right)$ 

active carboxylic acid site.

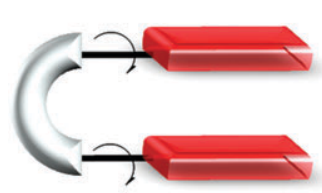

Zimmerman's tweezer rigidification. complexation with ester 20b $\left(K_{\mathrm{a}}<5 \mathrm{M}^{-1}\right)$. tectures (Fig. 13). the number and size of the spacer units. naphthalene-spaced receptors (Fig. 14). reduced to $7.6 \AA$ (Fig. 15). ${ }^{25}$

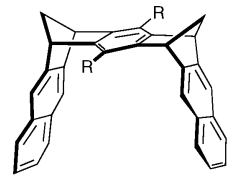

2A

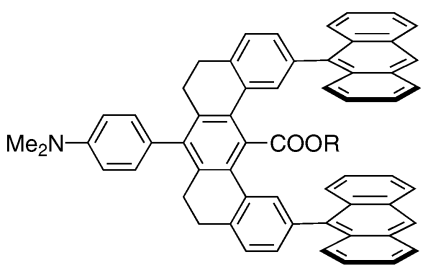

$20 \mathrm{a}: \mathrm{R}=\mathrm{H}, \mathrm{b}: \mathrm{R}=\mathrm{OMe}$

Fig. 12 Dibenz $[c, h]$ acridine-based molecular tweezers containing an

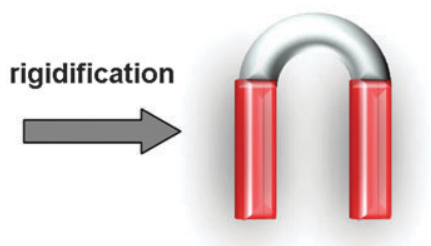

Klärner's tweezer
Fig. 13 Two families of molecular tweezers with different degrees of

9-adenine. ${ }^{8}$ The critical role of hydrogen bonding in the binding process was demonstrated by the absence of any

As shown above, these tweezers can modulate the cavity shape through rotation of the tips. Another family of molecular tweezers has been designed by Klärner and co-workers, who developed highly rigidified polyarene archi-

Hydrocarbon-based architectures di-, tri- and tetramethylenebridged compounds $\mathbf{2}, \mathbf{3}$ and $\mathbf{4}$, respectively, were synthesized through a convergent synthesis based on a molecular "Lego" set, consisting of bisdienophiles and dienes. ${ }^{7}$ These are arranged in a belt-like concave-convex topography, so that an aromatic guest might be sandwiched via multiple $\pi-\pi$ and $\mathrm{CH}-\pi$ interactions. To fit with the substrate topography, the size and shape of the receptor cavity can be tuned by varying

Dimethylene-bridged architectures $\mathbf{2}$ have been referred as molecular clips, because they form complexes by "clipping" an aromatic substrate inside the receptor cavity. The distance between both sidewalls can be tuned using benzene- or

The distance between the tweezer pincers in system $2 \mathrm{~A}$ $(\mathrm{R}=\mathrm{OMe})$ is $c a .10 \AA$ in the solid state before guest complexation, and reaction with 1,4-dinitrobenzene ( $p$-DNB) produces a host-guest complex in which this distance was

Thanks to larger van der Waals contact surfaces, molecular clips 2C with anthracene sidewalls form more stable

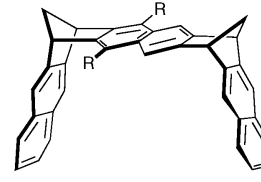

2B

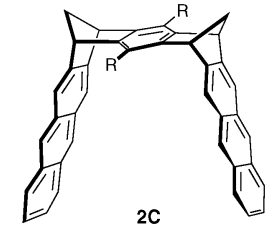

$2 \mathrm{C}$

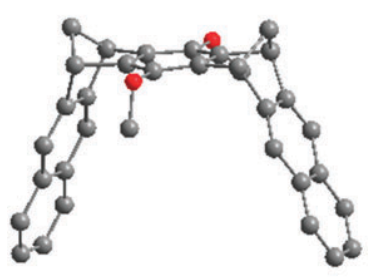

Fig. 15 Single-crystal structures of molecular clip $\mathbf{2 A}$ (left) and complex $p$-DNB@2A (right).

host-guest complexes with electron-deficient aromatic and quinoid molecules, such as the inclusion complex TCNB@2C $\left(\mathrm{R}=\mathrm{OH}, K_{\mathrm{a}}=12800 \mathrm{M}^{-1}\right.$ in $\left.\left.\mathrm{CDCl}_{3}\right)\right)^{26,27}$ Moreover, complexes TCNB@2C and TNF@2C (TNF=2,4,7-trinitro9-fluorenone) were described as the first examples of chargetransfer luminescence from host-guest complexes. These act as potential chemical sensors with characteristic color changes observed upon complex formation, from colourless to red or purple with TCNB, and from yellow to green with TNF.

An interesting extension of model derivative $\mathbf{2 A}$ corresponds to clip $\mathbf{2} \mathbf{A}^{\prime}$ bearing two chiral (-)menthyl groups at the extremity of the tips. The corresponding inherently molecular clips, pseudoenantiomeric anti and anti $i^{\prime}$, as well as mesoid syn, were separated by chiral HPLC (Fig. 16). Remarkably, compound $\mathbf{2 A}^{\prime}$ in its anti' form is able to discriminate between L- and D-tryptophane methyl esters with a relative binding constant ratio $K_{\mathrm{D}} / K_{\mathrm{L}}=3.5$ with $K_{\mathrm{D}}=13600 \mathrm{M}^{-1}$ in $\mathrm{THF}-\mathrm{MeOH}-\mathrm{H}_{2} \mathrm{O}(4: 1: 5){ }^{28}$

Trimethylene-bridged molecular clips $\mathbf{3 A}$ and $\mathbf{3 B}$ present a narrower shape and a remarkably high $K_{\mathrm{a}}$ value $(5.4 \times$ $10^{6} \mathrm{M}^{-1}$ in $\mathrm{CHCl}_{3}$ ) was observed for host $\mathbf{3 B}$, with TCNB guest (Fig. 17). ${ }^{27}$
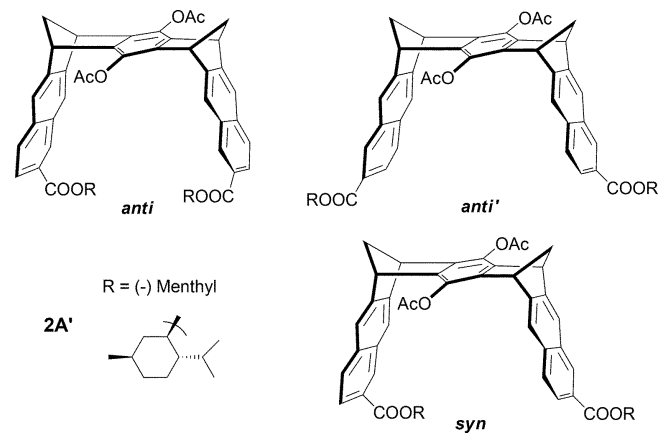

Fig. 16 Molecular clips $2 \mathbf{A}^{\prime}$ designed for supramolecular chiral discrimination.

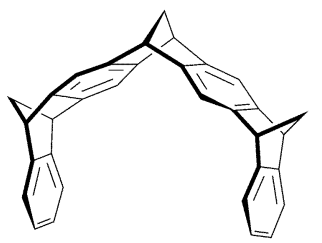

$3 A$

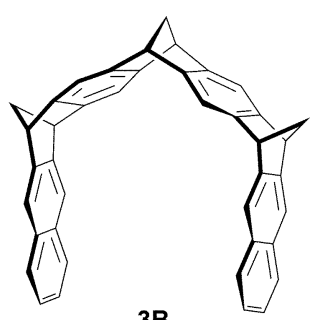

3B
Fig. 14 Dimethylene-bridged molecular clips.

Fig. 17 Some representative structures of trimethylene-bridged molecular tweezers. 


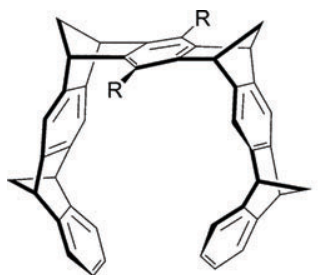

4A

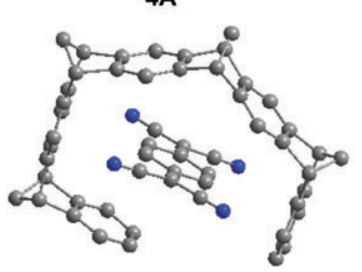

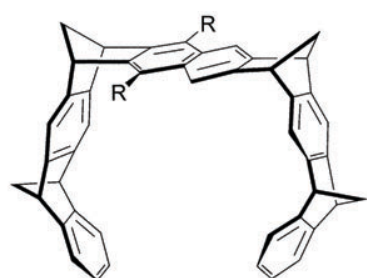

4B

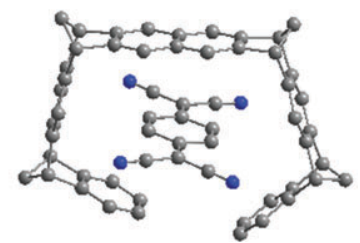

Fig. 18 Structures of tetramethylene-bridged molecular tweezers $4 \mathbf{A}$ and 4B. X-Ray structures of complexes TCNQ@4A (left) and TCNQ@4B (right).

The concept defined by Whitlock is slightly modified in compound $\mathbf{4}$ which is not far from being a macrocycle, and the pincers being not parallel, the guest can be considered as encapsulated by the host (Fig. 18). Consequently, contrary to the above-mentioned tweezers for which an aromatic guest is sandwiched in-between both tips, this one is arranged nearly parallel to the central naphthalene spacer unit in the case of receptors 4. Therefore, though guest $\mathbf{4}$ cannot be strictly considered as sandwiched, this case appears relevant with the topic of this review. Tweezer $4 \mathrm{~B}(\mathrm{R}=\mathrm{H})$ is a better receptor for substrate such as TCNQ $\left(K_{\mathrm{a}}>10^{5} \mathrm{M}^{-1}\right.$ in $\left.\mathrm{CDCl}_{3}\right)$ than $4 \mathrm{~A}(\mathrm{R}=\mathrm{H})\left(K_{\mathrm{a}}=1100 \mathrm{M}^{-1}\right.$ in $\left.\mathrm{CDCl}_{3}\right)$ since the complexation by the latter requires a substantial distortion of the receptor geometry (Fig. 18). ${ }^{7}$

The same tendency was observed with the 1,2,4,5-tetracyanobenzene (TCNB) guest as shown by respective X-ray crystal structures of TCNB@2C and TCNB@4B (Fig. 19). ${ }^{29}$

These clips and tweezers containing naphthalene or anthracene sidewalls form luminescent host-guest complexes with $\mathrm{TCNB}$ in $\mathrm{CHCl}_{3}$ solution resulting from predominant charge transfer interactions. Association/dissociation barriers formation $\left(\Delta G=-7.9 \mathrm{kcal} \mathrm{mol}^{-1}\right.$ for TCNB@4B and

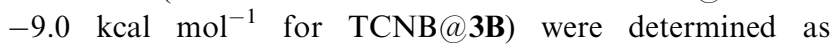
well as dissociation values of host-guest complexes $\left(\Delta G^{\#}=\right.$ $15.7 \mathrm{kcal} \mathrm{mol}^{-1}$ for TCNB $@$ 4B and $12.4 \mathrm{kcal} \mathrm{mol}^{-1}$ for TCNB@3B). These observations are consistent with the close topology of tweezers $\mathbf{4 B}$ which makes a kinetically rather
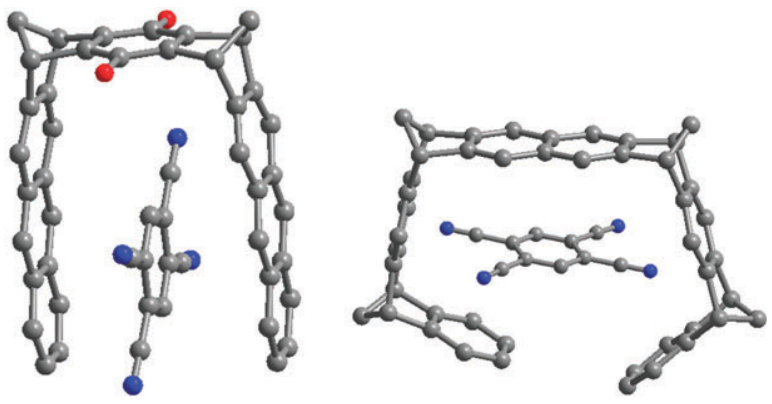

Fig. 19 X-Ray crystal structures of TCNB@2C and TCNB@4B complexes. difficult process the inclusion of a guest molecule. Contrariwise, clip 3B presenting a more opened shape allows an easier inclusion of the guest molecules, which is accompanied by a lower activation barrier. ${ }^{27}$

The versatility of the synthesis which is supported by cycloaddition processes, allowed an access to water-soluble systems. Corresponding receptors exhibit a good selectivity in substrate binding in aqueous solution. For instance, tweezers 4B and clip 2C $\left(\mathrm{R}=\mathrm{OP}\left(\mathrm{CH}_{3}\right) \mathrm{O}_{2}{ }^{-} \mathrm{Li}^{+}\right)$form highly stable host-guest complexes with the enzyme cofactor model $N$-methylnicotinamide iodide (NMNA) in methanol $\left(K_{\mathrm{a}}=\right.$ $11.9 \times 10^{4} \mathrm{M}^{-1}$ in $\mathrm{CD}_{3} \mathrm{OD}$ for $\mathbf{4 B}$ and $1.04 \times 10^{4} \mathrm{M}^{-1}$ for $\mathbf{2 C}$ ) and water as well. ${ }^{30}$

Triptycene was also found to be a useful three-dimensional Y-shaped building block for the construction of a new class of rigidified polyarene receptors. This is for example illustrated with the triptycene-based bis(crown ether) host 21, which incorporates two dibenzo-24-crown-8 ether moieties, and which was shown to form stable clip-shaped complex with paraquat (Fig. 20). ${ }^{31}$ A charge transfer from the electron-rich host to the electron poor paraquat $\left(K_{\mathrm{a}}=16300 \mathrm{M}^{-1}\right.$ in $\mathrm{CD}_{3} \mathrm{CN}$ ) is observed. X-Ray crystal structure shows that the complexation process involves multiple $\mathrm{CH}$... O hydrogen bonds between the paraquat unit and ether oxygen atoms, but also $\pi$-stacking interactions between paraquat ring and aromatic rings of the receptor.

A recent extension to the $\mathrm{H}$-shaped scaffold pentiptycenebased bis(crown ether) host 22 incorporating two dibenzo-24crown- 8 ether moieties has been proposed. ${ }^{32}$ It exhibits an efficient complexation ability toward cyclobis(paraquat- $p$ phenylene) in solution $\left(K_{\mathrm{a}}=2650 \mathrm{M}^{-1}\right.$ in $\left.\mathrm{CD}_{3} \mathrm{CN}\right)$ (Fig. 21).

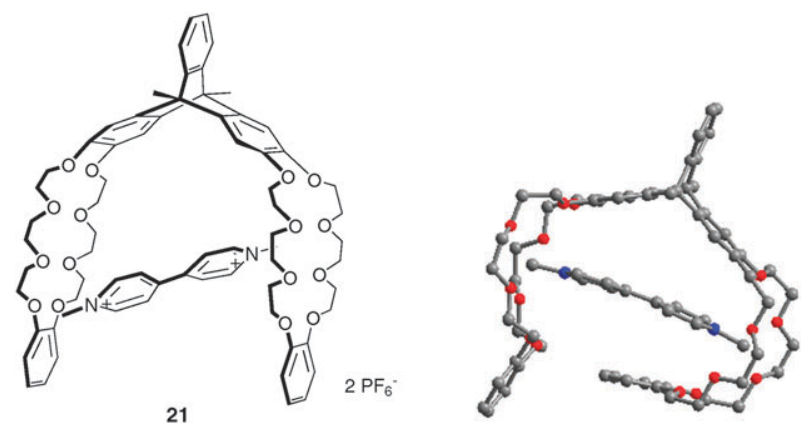

Fig. 20 Complexation of paraquat with triptycene-based molecular clip 21 and corresponding X-ray crystal structure (anions omitted).

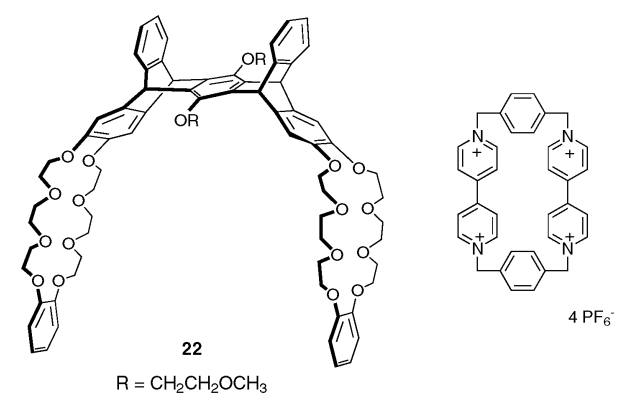

Fig. 21 Structures of pentiptycene-based molecular clip 22 and cyclobis(paraquat- $p$-phenylene). 


\subsection{Rigid Kagan's ethers and chiral Tröger's bases}

The perpendicular arrangement $\left(93^{\circ}\right.$ angle) of two aromatic rings found in Kagan's ether $\mathbf{2 3}$ constitutes a powerful scaffold for constructing receptors capable of aromatic guests binding with both face-to-face and face-to-edge interactions. On this basis, a class of molecular tweezers was initially developed with analogs of Kagan's ether. ${ }^{33}$ The complex between tweezers 24 and 1,3,5-trinitrobenzene (TNB) was crystallized showing the TNB guest is parallel to the dibenzofurane units with a distance of $3.32 \AA$ in agreement with a stacking interaction between the two systems ${ }^{34}\left(K_{\mathrm{a}}=2000 \mathrm{M}^{-1}\right.$ in $\left.\mathrm{CHCl}_{3}\right){ }^{6}$ Fukazawa and Coll developed the dioxa[2,2]orthocyclophane $\mathbf{2 5}$ which presents a tweezers-type arrangement with two terminal aromatic rings separated by $6.5 \AA$ in the syn conformation. ${ }^{35}$ This was demonstrated by the binding affinity of host $\mathbf{2 6}$ for TCNQ guest. This one is suitably positioned for combining stacking interactions with the terminal naphthalene and phenanthrene chromophores, and an edge-to-face interaction with the central durene bridge (Fig. 22). ${ }^{36}$ The highest association constants were obtained with pyromellitic dianhydride (PDA) or TCNB $\left(\mathrm{Ka}=1000 \mathrm{M}^{-1}\right.$ for PDA@26 and TCNB@26).

The development of chiral molecular tweezers is of particular interest because they will contribute to new research avenues in chiral supramolecular chemistry and related applications. ${ }^{6}$ Tröger's base provides a relatively rigid chiral skeleton with the requirements for the construction of molecular tweezers. Dolenský and Coll. recently described largepincered molecular tweezers 27 based on a bis-Tröger's base for which the calculated lateral pincers lie almost parallel to each other $\left(32^{\circ}\right)$ with a distance of $6.7-8 \AA$ between them (Fig. 23). ${ }^{37}$ The syn isomer, unlike the anti isomer, was shown to form a charge-transfer complex with tetracyanoethylene (TCNE) characterized by a color change from colourless (anti)

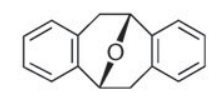

23

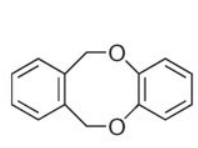

25

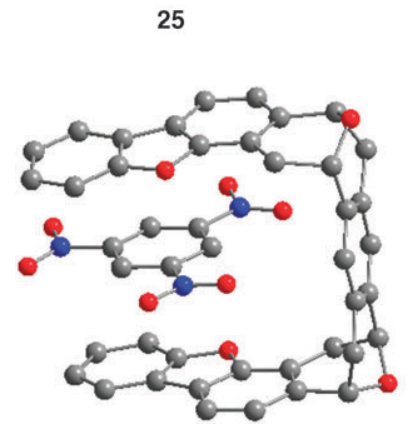

Fig. 22 X-Ray crystal structures of TNB@24 (left) and TCNQ@26 (right) complexes.

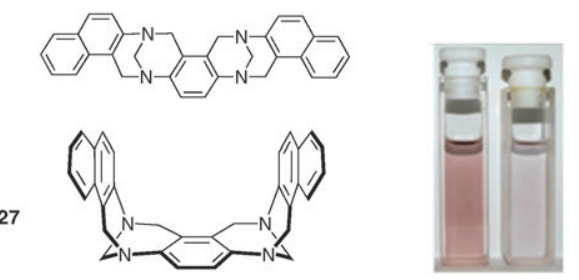

Fig. 23 Structure of Tröger's base molecular tweezer and color change observed with the complexation of TCNE by 27 syn (reproduced with permission from ref. 37. Copyright American Chemical Society 2010).

to darker (syn) purple solution. It should be noted that the inherent chirality in the cleft has not been yet exploited in molecular recognition studies, although enantioselective recognition is possible. ${ }^{38}$

\subsection{Concave polycyclic aromatic hydrocarbons for fullerene recognition}

Beside usual host systems which are designed for recognition of planar guests between pincers of a molecular tweezer, a novel type of molecular receptors has been recently introduced with curved conjugated carbon networks as bowl-shaped polycyclic aromatic hydrocarbons. Their accessible concave surfaces appear to be ideal recognizing curved-surface fullerenes through concave-convex $\pi-\pi$ interactions. $^{39}$ The first experimental evidence was provided by the formation of a stable inclusion complex of $\mathrm{C}_{60}$ with the "buckycatcher" 28, a molecular clip with two corannulene pincers and a tetrabenzocyclooctatetraene tether (Fig. 24). The inclusion complex $\mathrm{C}_{60} @ \mathbf{2 8}$ was crystallized showing a distance between corannulene units and $\mathrm{C}_{60}$ surface close to $3.1 \AA$ and complexation was also evidenced in solution $\left(\mathrm{Ka}=8600 \mathrm{M}^{-1}\right.$ in toluene- $\left.d_{8}\right){ }^{40}$ Molecular clip 29, a more flexible analog of the buckycatcher $\mathbf{2 8}$, was shown to encapsulate only solvating molecules of nitrobenzene in the solid state. $^{41}$

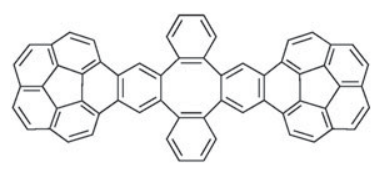

28

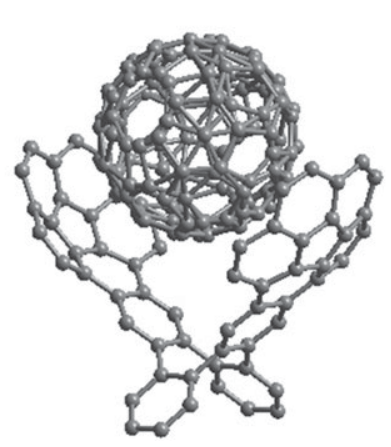

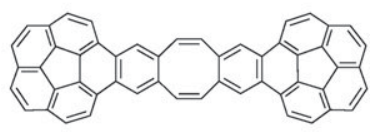

29

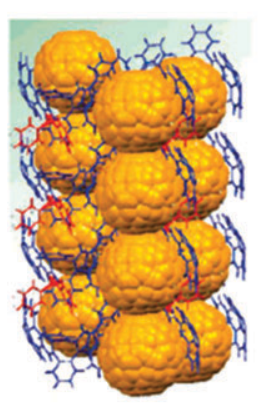

Fig. $24 \mathrm{X}$-Ray crystal structure of $\mathrm{C}_{60} @ \mathbf{2 8}$ and corresponding crystal packing pattern (reproduced with permission from ref. 40. Copyright American Chemical Society 2010). 


\section{Tweezers involving flexible platforms}

The platform which bridges both pincers of the tweezers can be flexible by its own, or through an intermediate linker, if any. For such systems, both binding sites do not necessarily adopt a cofacial arrangement, and an external stimulus, such as a binding event, can induce a conformational rearrangement. This process often requires large reorganization energies which generally result in lower association constants in host-guest complexes compared to what occurs with rigid tweezers. Conversely, such flexible systems are often more straightforward to synthesize and they can adjust to the size of the substrate. Significant new inputs have been described in this family of tweezers, involving in particular electronrich tips.

\subsection{Electron-rich flexible tweezers}

3.1.1 Flexible tweezers with pendant $(+)$ usnic acid units. Using a $(1 R, 2 R)$-1,2-diaminocyclohexane platform, complexation of 2,4,7-trinitrofluorenone (TNF) between two (+)-usnic acid as pincers could be observed in molecular tweezer 30. In this system, both chromophores are separated by a distance of ca. $7.5 \AA$ in the solid state, a distance which decreases to $6.9 \AA$ upon binding TNF. Though binding constant appears moderate $\left(K_{\mathrm{a}}=72 \mathrm{M}^{-1}\right.$ in $\left.\mathrm{CD}_{2} \mathrm{Cl}_{2}\right)$ a strong colour change appears upon complex formation, which is assigned to a charge-transfer complex between $\mathbf{3 0}$ and TNF (Fig. 25). ${ }^{42}$

3.1.2 Flexible tweezers with pendant pyrene units. An illustration of a straightforward access to a flexible tweezers molecule has been proposed by Colquhoun and Coll with systems 31 and 32. These involve isophthaloyl or pyridine-2,6dicarbonyl platforms, respectively. ${ }^{43}$ This colourless tweezer bears pendant pyrene units as donors, and exhibits a
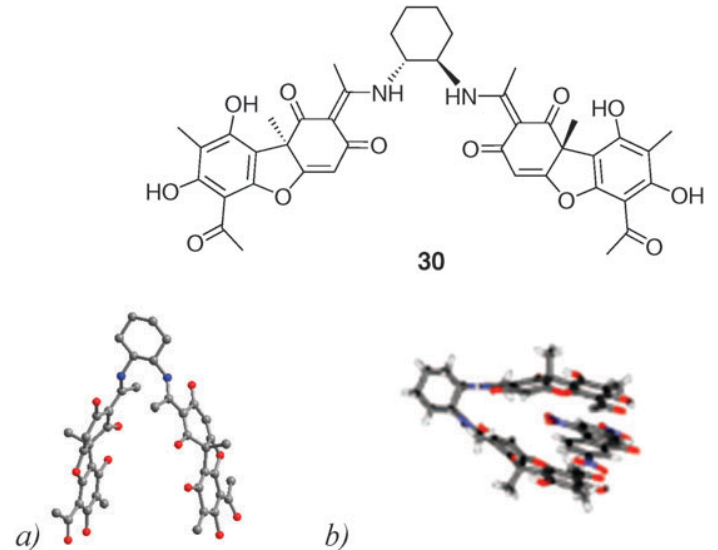

b)
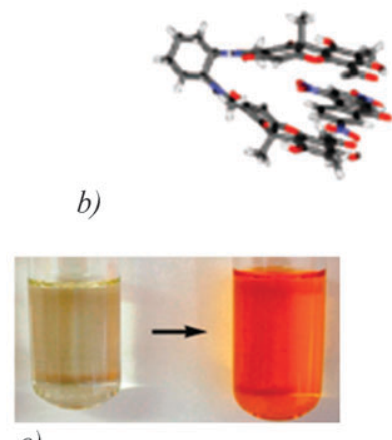

c)

Fig. 25 X-Ray crystal structures of (a) molecular tweezer 30; (b) the corresponding TNF complex and (c) color change upon TNF binding by tweezer 30 (reproduced with permission from ref. 42. Copyright American Chemical Society 2010).

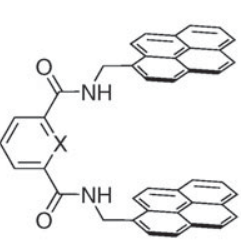

$31 \mathrm{X}=\mathrm{CH}$

$32 \mathrm{X}=\mathrm{N}$
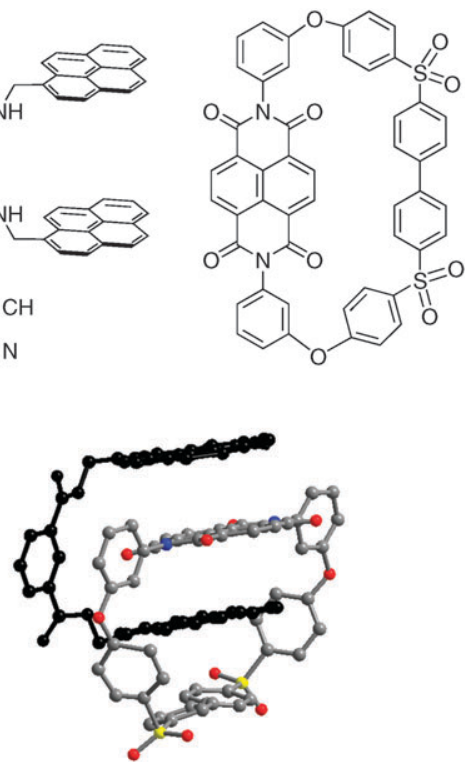

Fig. 26 Structures of tweezers 31 and 32; X-ray crystal structure of a $1: 1$ complex between tweezer $\mathbf{3 1}$ and a macrocyclic ether-imidesulfone.

remarkably high binding ability for $\pi$-acceptor macrocyclic derivatives involving a naphthalenediimide residue $\left(K_{\mathrm{a}}=\right.$ $24300 \mathrm{M}^{-1}$ in $\mathrm{CHCl}_{3} /$ hexafluoro-propan-2-ol (6:1)), which is manifested by a deep red colour change. It is worth noting that the high binding ability results from an original combination of mutually complementary $\pi-\pi$ stacking interactions between the tweezers and the macrocyclic guest, in addition to $\mathrm{NH}$... O and $\mathrm{CH} \cdots \mathrm{O}$ hydrogen bonds (Fig. 26). Interestingly, such set of interactions between tweezer $\mathbf{3 1}$ and complementary accepting moieties, could be extended to the recognition of specific monomers sequences in copolyimides macromolecules. ${ }^{44}$

In order to increase the number of binding interactions, an approach developed by the same group was to design new electrodeficient molecular tweezers $\mathbf{3 3}$ bearing two naphtalenediimide (NDI) units, complementary to the above-mentioned electron-rich systems 31. A 1:1 tweezer-tweezer complex is formed by mixing $\mathbf{3 1}$ and $\mathbf{3 3}$, each of the $\pi$-electron poor diimide units being able to maintain face-to-face strong binding interactions with the $\pi$-electron rich pyrene guest (Fig. 27). ${ }^{45} \mathrm{~A}$ characteristic deep red solution corresponding to the charge transfer was formed with a binding constant of $K_{\mathrm{a}}=3500 \mathrm{M}^{-1}\left(\mathrm{CHCl}_{3}\right)$.

Chiral molecular tweezers using a bile acid scaffold and pyrene-sidewalls have also been designed to bind electrondeficient aromatic species (Fig. 28) ${ }^{46}$ The two pyrene units in compound 34 are separated by $c a .6-6.5 \AA$ on the C-3 and
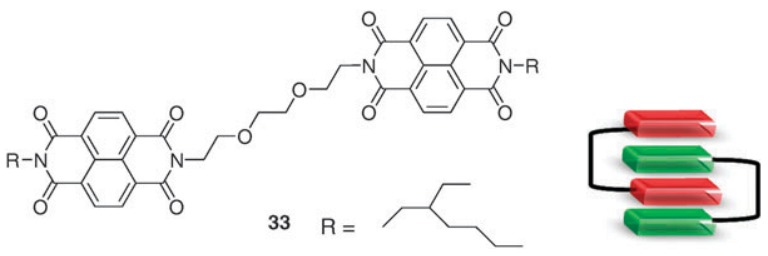

Fig. 27 Bis-NDI tweezer 33 and association model for donoracceptor tweezers 31-33. 

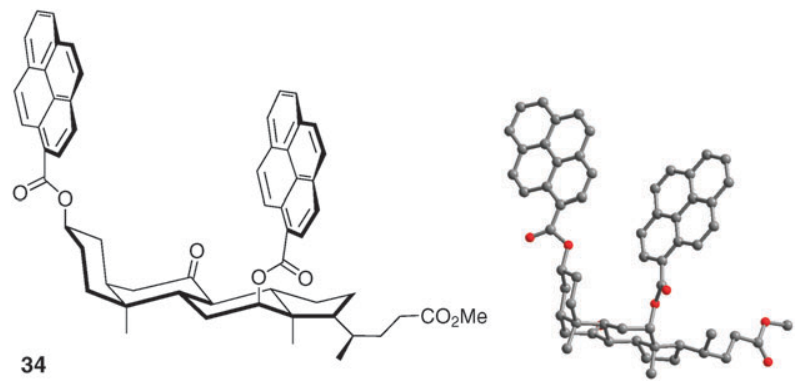

Fig. 28 Structure of chiral bile acid molecular tweezer 34.

C-12 positions of the rigid bile acid backbone. The resulting clip allows moderate association constants with polynitroaromatic compounds (e.g. $K_{\mathrm{a}}=220 \mathrm{M}^{-1}$ for $\mathrm{TNF}$ in $\mathrm{CDCl}_{3}$ ).

3.1.3 Flexible tweezers with pendant electron-rich tetrathiafulvalene-based units. The $\pi$-donating ability of TTF framework is well established. This system has proven to be an efficient building block in various topics of supramolecular chemistry ranging from electrochemical sensing to switchable architectures. ${ }^{47}$ We showed above that TTF can be integrated in rigid glycoluril based molecular tweezer $\mathbf{1 6}$ and we present now few examples involving flexible systems.

In the active field of molecular receptors designed for recognition of fullerenes in solution, the concept of concave receptors appears particularly promising besides the welldescribed poly-porphyrinic systems. ${ }^{11}$ As studied by Martín and Coll., a prototypal unit is proposed with the concave aromatic $\pi$-extended TTF which presents a good shape complementarity with the convex buckyball. ${ }^{48} \mathrm{~A}$ straightforward preparation of tweezers molecules using the flexible isophthalic platform has been developed recently. ${ }^{49}$ These systems incorporate extended-tetrathiafulvalene (exTTF) units as binding sites (Fig. 29). Tweezer molecule 35 exhibits a good binding ability for $\mathrm{C}_{60}\left(K_{\mathrm{a}} \approx 3000 \mathrm{M}^{-1}\right.$ in chlorobenzene $) .{ }^{50}$ Depending on the solvent, the resulting $1: 1$ complex appears either as one fullerene sandwiched between two exTTF units (chlorobenzene) or to exist as a supramolecular tetramer $\left(\mathrm{CHCl}_{3}-\mathrm{CS}_{2}\right)$.

As an extension to this system, fullerene-exTTF tweezer monomer $\mathbf{3 6}$ was designed to self-assemble in a head-to-tail fashion through recognition of the $\mathrm{C}_{60}$ moiety by the exTTF pincer-like receptor (Fig. 30). ${ }^{51}$ The recognizing units are complementary both at the structural and electronic levels and self-associate to produce a linear head-to-tail supramolecular
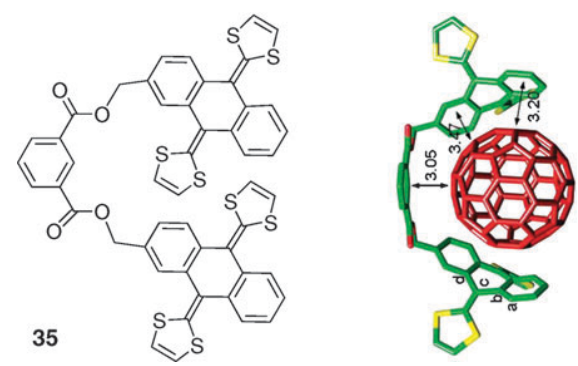

Fig. 29 Molecular tweezer 35 and the calculated 35. $\mathrm{C}_{60}$ complex at the $\mathrm{BH} \& \mathrm{H} / 6-31 \mathrm{G}^{* *}$ level. (Reproduced with permission from ref. 50. Copyright Royal Society of Chemistry 2010.)

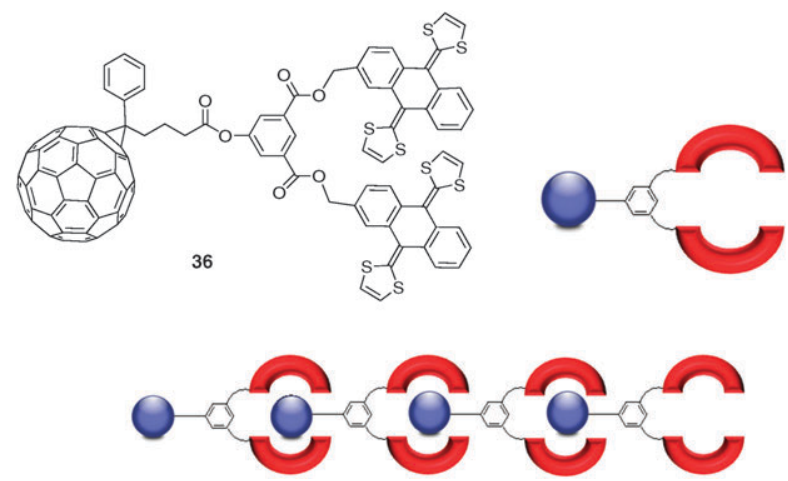

Fig. 30 Chemical structure of molecular tweezer 36 and illustration of the resulting supramolecular donor-acceptor polymer.

polymer (Fig. 30). This arrangement prevents $\mathrm{C}_{60}$ aggregation and provides a promising new entry into $\mathrm{D}-\mathrm{A}$ devices.

Concave-convex interactions in host-guest complexes from 35 (or 36) and $\mathrm{C}_{60}$ unit seem to play a role in the binding process. ${ }^{39}$ This contribution in stabilizing the supramolecular system has been illustrated by a comparative study of the $\mathrm{C}_{60}$ binding ability of tweezers $\mathbf{3 5}, \mathbf{3 7 - 3 9}$. These are all built from an isophthalic diester spacer grafted with two recognizing units, ${ }^{50}$ i.e. concave donating units (35), concave accepting unit (37), planar accepting units (38) and planar donating units (39) (Fig. 31). Such a collection of compounds allowed an investigation of the relative contributions of $\pi-\pi$, van der Waals, electrostatic, and concave-convex interactions upon recognizing $\mathrm{C}_{60}$. On the basis of ${ }^{1} \mathrm{H}$ NMR titration experiments and density functional theory (DFT) calculations, it appears that concave-convex complementarity contributes to the binding process, even if quantitatively small. This is illustrated in particular with compound $\mathbf{3 5}$ which presents the highest affinity for $\mathrm{C}_{60}\left(K_{\mathrm{a}}=3000 \mathrm{M}^{-1}\right.$, $\left.\mathrm{CDCl}_{3}-\mathrm{CS}_{2} 1: 1\right)$. The case of receptors 37 and 38 is also informative. In spite of the more electron-poor character of 37 when compared to $\mathbf{3 8}$, its binding constant towards $\mathrm{C}_{60}$ is larger $\left(37: K_{\mathrm{a}}=1540 \mathrm{M}^{-1}, \mathbf{3 8}: K_{\mathrm{a}}=790 \mathrm{M}^{-1}\right)$. Finally, no $\mathrm{C}_{60}$ binding is observed with 39 , presenting planar donating units. Note that extension of this strategy can be applied to non-symmetrical tweezers able to bind carbon nanotubes. ${ }^{52,53}$
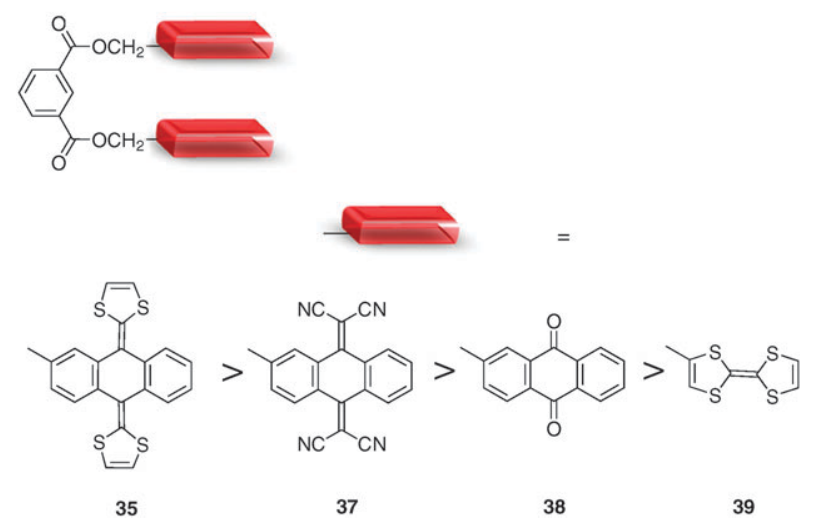

Fig. 31 Chemical structures of molecular tweezers 35, 37-39, associating an isophthalic diester spacer with various recognizing units. 


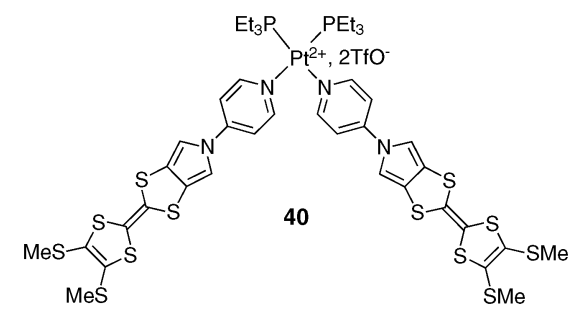

Fig. 32 Chemical structure of monopyrroloTTF dimer $\mathbf{4 0}$.

At this stage, it is worth noting that a Pt(II)-assembled monopyrroloTTF (MPTTF) dimer $\mathbf{4 0}$ has been very recently described, ${ }^{54}$ and shows a good affinity for $\mathrm{C}_{60}\left(K_{\mathrm{a}}=\right.$ $\left.1400 \mathrm{M}^{-1}, \mathrm{CH}_{2} \mathrm{Cl}_{2}\right)$. Such affinity is in this case assigned to a greater $\pi$-extension of the MPTTF donating framework related to the TTF backbone in 39, and to the presence of the metallic cation (Fig. 32).

J. O. Jeppesen et al. described recently molecular tweezer $\mathbf{4 1}$ which assembles two MPTTF units and two thiophene moieties within a calix ring (Fig. 33). ${ }^{55}$ Whereas this system adopts an extended conformation in the solid state, a tweezerlike 1,3-alternate conformation with one acceptor TCNQ sandwiched between the two electron-rich MPTTF units was observed. This complexation results from donor-acceptor interactions, and is characterized in the solid-state by an interplanar distance between the two MPTTF units of ca. $6.7 \AA$, and $3.3 \AA$ between MPTTF and TCNQ units. Solution studies (UV-vis-NIR and ESR, $\mathrm{CH}_{2} \mathrm{Cl}_{2}$ ) also showed that a charge transfer takes place between the MPTTF units and TCNQ.

According to a similar strategy as for compound $\mathbf{2 6}$ involving the dioxa[2.2] orthocyclophane skeleton, ${ }^{36}$ a flexible system incorporating redox-active TTF units has been recently proposed by Azov and Coll with compound 42 (Fig. 34) ${ }^{56}$ Two TTF moieties are in this case connected to the opposite sides of a 1,2,4,5-substituted benzene scaffold via 8-membered dithia rings. Such architecture is relatively rigid and
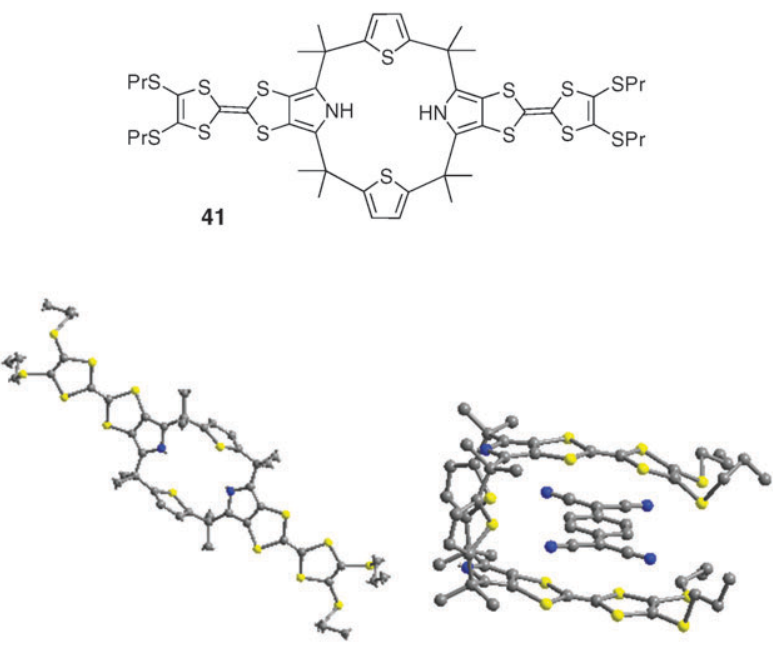

Fig. 33 X-Ray structures of compound 41 (left) and corresponding sandwich TCNQ complex (right) (solvent molecule and a second TCNQ molecule located between two adjacent $\mathbf{4 1}$ molecules are omitted).

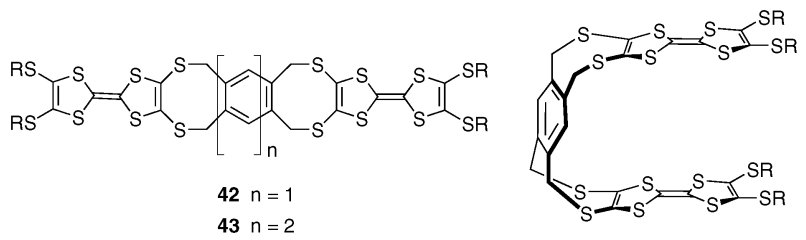

Fig. 34 Bis-TTF based molecular tweezers developed by Azov and Coll.

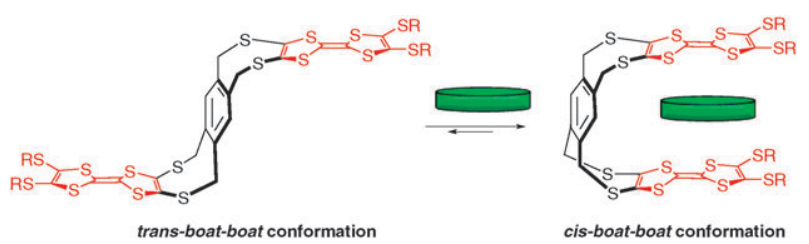

Fig. 35 Equilibrium between the trans boat-boat conformation (among other conformations) of $\mathbf{4 2}$, and the closed cis boat-boat conformation suitable for sandwiching electron-poor aromatic guests.

conformational analysis of cycloocta-1,5-diene-like ring systems indicates the existence of three low energy boat, chair, and skew conformations. Only the cis-boat-boat conformation shows a tweezer-like arrangement, with the TTF planes positioned almost parallel at $c a$. $6 \AA$ away from each other (Fig. 35). All possible combinations of boat, chair and skew conformations have been shown to roughly lie within a 2-4 $\mathrm{kcal} \mathrm{mol}^{-1}$ energy window.

An extension of this system has been proposed by the same authors by incorporating a naphthalene backbone instead of a benzene ring (compound 43), thus controlling the intra TTF-TTF distance within the clip. ${ }^{57}$ Molecular recognition experiments carried out with $\mathbf{4 2}$ and $\mathbf{4 3}$ show relatively low binding properties with 2,4,7-trinitro-9-fluorenylidenemalonitrile $\left(K_{\mathrm{a}}=16 \mathrm{M}^{-1}\right.$ and $22 \mathrm{M}^{-1}$ for $\mathbf{4 2}$ and $\mathbf{4 3}$, respectively, $\mathrm{CDCl}_{3}$ ), whereas only tweezer $\mathbf{4 3}$ exhibits a very weak binding with TCNB $\left(K_{\mathrm{a}}=6 \mathrm{M}^{-1}\right)$. Therefore, these clip-like architectures present a non pre-defined topology and sufficient conformational freedom to adopt the cis-conformation required for host recognition thanks to a large-scale openclose molecular movement. In a closed conformation the two tips of the tweezers overlay each other, whereas in an opened conformation the tips are located opposite to each other.

Another interesting feature of such kind of clips relies on their electrochemically-driven dynamic properties. ${ }^{56,57}$ Oxidation of $\mathbf{4 2}$ at the first TTF redox level is characterized on the cyclic voltammogram, by two TTF units in close interaction. Conversely, oxidation at the TTF dication state shows that the two redox-active units are no longer in interaction and at a larger distance. This observation results from coulombic repulsive interactions between the two doubly positively charged TTF units. Consequently, whereas a closed ( $c i s$ ) conformation is likely preferred at least when the system is oxidized at the mono-oxidized state, a conformational transition to an opened conformation is obtained at the fully oxidized state. This observation is supported by variable temperature NMR studies led on the $-\mathrm{SCH}_{2}$ groups. Such architectures offer promising perspective for the construction of electrochemically responsive molecular machines endowed with a controlled movement. 


\subsection{Tunable flexible tweezers}

Molecules that can change their conformations (rotation, shuttling, flipping, bending) in response to various stimuli offer a potential to be used in constructing molecular machines or devices, which is the case of molecular tweezers.

3.2.1 Flexible tweezers triggered by a redox stimulus. Compound 42 described above, constructed around a dioxa[2.2]orthocyclophane central platform and bearing two redox-active TTF units, allows a redox-driven control over opened and closed conformations of the tweezer. The redox stimulus operates in this case on the charge state of the lateral tips of the tweezers. Another recent example of a redoxcontrol over tweezers conformations was reported with compound $\mathbf{4 4}$ bearing two terminal thiol groups (Fig. 36) ${ }^{58}$ In this case, a change is observed from an opened conformation in the dithiol state 44a to a closed conformation upon oxidation $\left(\mathrm{I}_{2}\right.$, pyridine) in the disulfide state $(\mathbf{4 4 b})$. Moreover, the process appears reversible through reductive cleavage of the disulfide bond using tri- $n$-butylphosphine. Closed and opened conformations were both characterized in solution $\left({ }^{1} \mathrm{H} \mathrm{NMR}\right)$ and in the solid state (X-ray structure). The preferred cleft conformation in the disulfide form (44b) is assigned to intramolecular $\mathrm{CH} / \pi$ attractive interaction between the alkyl ring and both terminal naphthalene rings.

3.2.2 Flexible tweezers triggered by anion binding. J. O. Jeppesen and J. L. Sessler have recently developed a calix[4]pyrrole scaffold incorporating four appended TTF units (Fig. 37). ${ }^{59,60}$ In a way, compound 45 can be considered as a double tweezer-like model, since it can exist in two remarkable controllable conformations. In its 1,3-alternate conformation, this system acts as an effective receptor for neutral electrondeficient molecules such as 1,3,5-trinitrobenzene (TNB), tetrafluoro- $p$-benzoquinone, tetrachloro- $p$-benzoquinone, and $p$-benzoquinone which are sandwiched between TTF pairs. The interplanar distance within pairs of TTF is in the range of 6.80-7.10 А. Intercalation of the guest results in a colour change from yellow to green, characteristic of a charge transfer. Interestingly, this recognition process is blocked by the addition of chloride anion which induces a conformational change from the 1,3-alternate to the corresponding cone conformation, resulting in guests release. This change is promoted by a cooperative binding of chloride anion by the four NH pyrrole units. Regeneration of the 1,3-alternate conformation can be carried out by extraction of chloride anion with water. On the other hand, the ability of the cone conformation for encapsulation of spherical electron-deficient $\mathrm{C}_{60}$ could also be demonstrated.

These results were recently extended with a second generation of TTF-calix[4]pyrroles compounds such as $\mathbf{4 6}$ which,

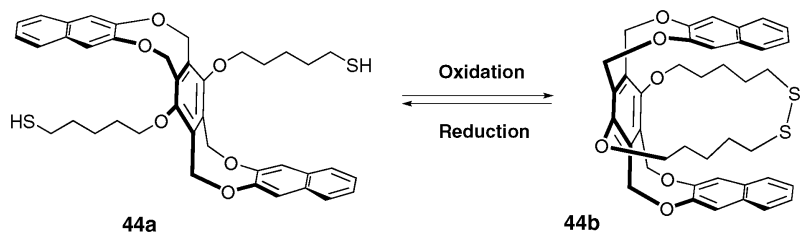

Fig. 36 Opened and closed conformations of compound $\mathbf{4 4 .}$
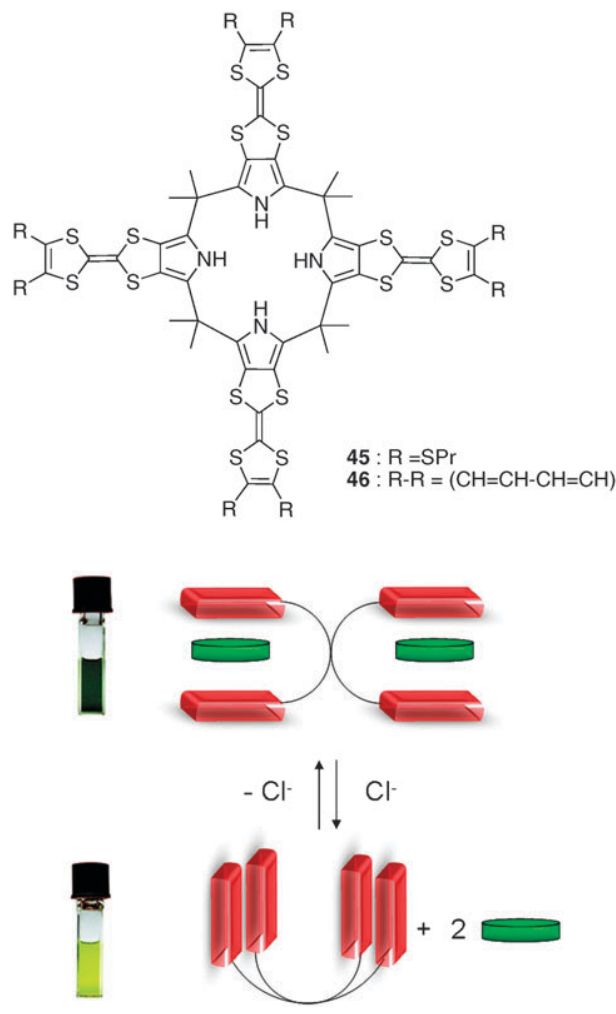

Fig. 37 Dynamic behaviour of receptor 45 with an electron-poor guest and chloride anion (reproduced with permission from ref. 59 . American Chemical Society 2010).

thanks to an additional fused aromatic ring on each TTF tip, presents a higher $\pi$-surface compared with $\mathbf{4 5}$. This compound was designed to better match flat electron-deficient guests in terms of size and shape. The authors could demonstrate that such systems exhibit a positive homotropic allosteric effect upon guest binding, and a significantly enhanced colorimetric response to nitroaromatic compounds (TNB, picric acid, TNP, and 2,4,6trinitrotoluene TNT), positioning this system as highly efficient chemosensors for nitroaromatic explosives (Fig. 38). ${ }^{61}$

\subsubsection{Flexible tweezers triggered by metal cation binding}

Lehn and Coll have designed a series of dynamic devices undergoing ion-induced conformational changes that

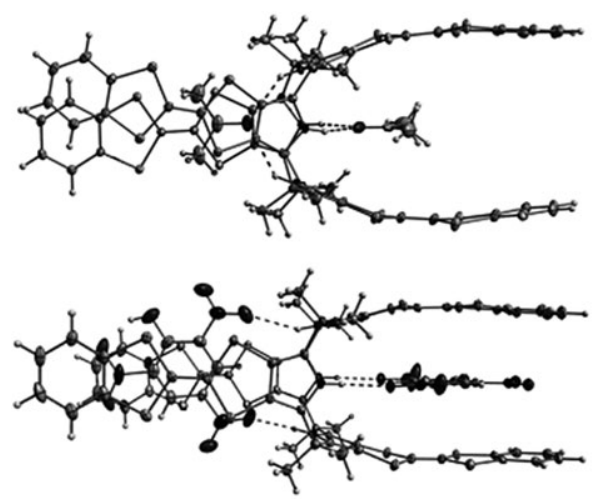

Fig. 38 X-Ray crystal structures of $\mathbf{4 6} \cdot 2 \mathrm{Me}_{2} \mathrm{CO}$ (top) and $\mathbf{4 6} \cdot 2 \mathrm{TNP}$ (bottom) (reproduced with permission from ref. 61. Copyright Wiley-VCH 2010). 
modulate affinity for the substrate. These bistable receptors are built either around a terpyridine scaffold or a pyridinepyrimidine-pyridine sequence, which self-converts from a $\mathrm{W}$ to a $\mathrm{U}$ shape ( $\mathrm{U}$ to $\mathrm{W}$, respectively) upon cation coordination. These systems present a tweezer-like behaviour under the $\mathrm{U}$ form which is well-suited for guest intercalation. Therefore, the binding (or release) of a given substrate is controlled through a shape switching of the receptor which is induced by metal-ion coordination. For instance, compound 47 adopts a U-shaped tweezer-like conformation with two tips (anthracene units) well positioned to sandwich a substrate (Fig. 39). ${ }^{62} \mathrm{~A}$ colour change due to charge transfer complexation is instantaneously observed upon introduction of electronacceptors (TNF, TCNQ), and intercalation is evidenced in solution ( ${ }^{1} \mathrm{H}$ NMR study) as well as in the solid state. The crystal structure shows that the two anthracene donors are separated by $7 \AA$ and are almost parallel (Fig. 40). The introduction of $\mathrm{Cu}\left(\mathrm{CH}_{3} \mathrm{CN}\right)_{4}, \mathrm{BF}_{4}$ to this solution leads to a switching from the tweezer-form (U) to the $\mathrm{W}$ conformation, with a releasing of the substrate which can be monitored by ${ }^{1} \mathrm{H}$ NMR and a loss of the charge transfer colour.

Conversely, replacing the central pyrimidine ring with a pyridine unit leads to a complementary behaviour, with the U-shape occurring upon cation complexation. An interesting example is provided with compound 48 (Fig. 41). Mixing this compound with one equivalent of a coordinating ligand (1,10-phenanthroline) in presence of a zinc triflate salt, produces a sandwich complex in which the metal cation induces the U-form and contributes also to bind the phenanthroline guest by coordination (Fig. 42). Noteworthy, no binding was observed for $\mathbf{4 8}$ with non-coordinating electron-poor guests such as TNF and TCNQ. This is presumably due to a pinching of the terpyridine backbone upon metal complexation and by obstruction of the cavity space by the solvation sphere of the octahedral cation, which prevent intercalation of any guest between the tips. This is not any more the case with analog $\mathbf{4 9}$, possessing an amide spacer, and ensuring a higher spatial separation between the

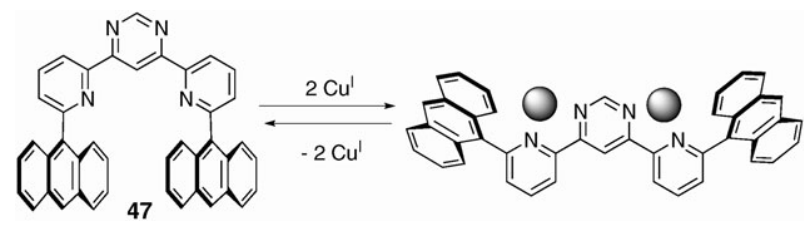

Fig. 39 Cation-driven two-stage U (left)/W (right) molecular shape switching.

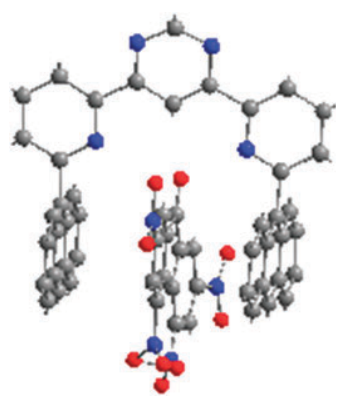

Fig. 40 X-Ray crystal structure of the complex 47 . TNF.

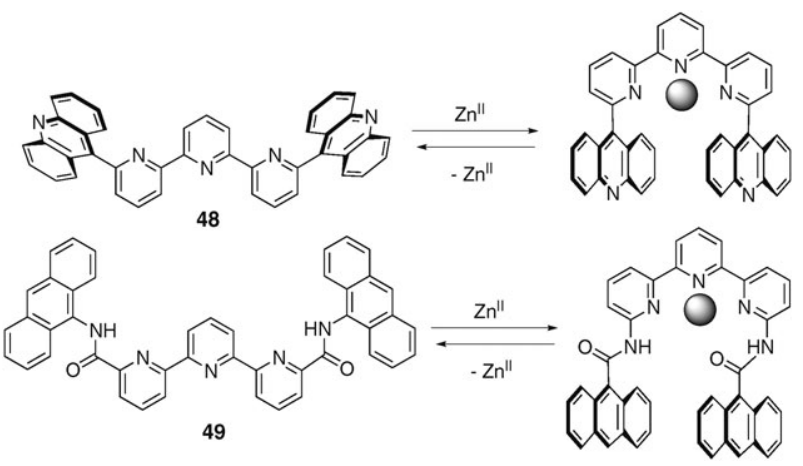

Fig. 41 Cation-driven two-stage W (left)/U (right) molecular shape switching.

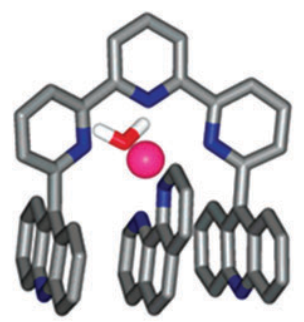

Fig. 42 X-Ray crystal structure of the sandwich complex $48 \cdot \mathrm{Zn}$ (II). Phen (reproduced with permission from ref. 62. American Chemical Society 2010).

coordination site and the intercalation pocket. When the $\mathrm{Zn}$ (II) complex is titrated with TCNQ or TNF, intercalation occurs and the expected charge transfer is now observed.

The tritopic ligand $\mathbf{5 0}$, which combines one terpyridine and two pyridine subunits was used by Barboiu and Coll to reach self-complementary molecular clefts which are stabilized by strong $\pi-\pi$ stacking interactions. Such supramolecular assemblies result from the binding of octahedral metal ions $\mathrm{Co}^{2+}$ or $\mathrm{Pb}^{2+}$ ions (Fig. 43) ${ }^{63}$ through orthogonal-terpyridine
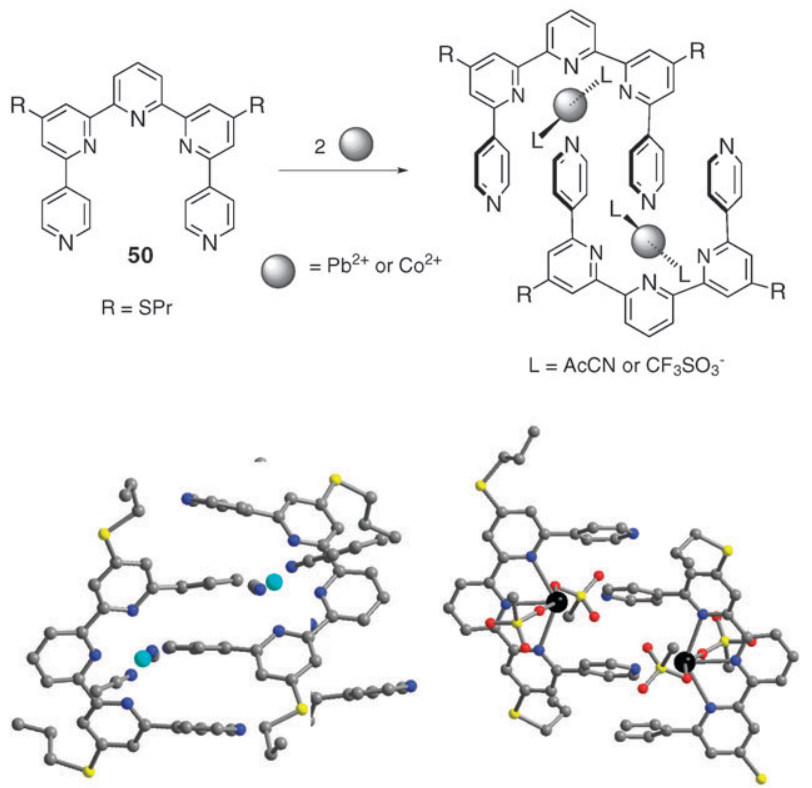

Fig. 43 Preparation and $\mathrm{X}$-ray crystal structures of duplex cleft complexes $\left[\mathrm{Co}_{2}(\mathbf{5 0})_{2}\left(\mathrm{CH}_{3} \mathrm{CN}\right)_{4}\right]^{4+}$ (left) and $\left[\mathrm{Pb}_{2}(\mathbf{5 0})_{2}\left(\mathrm{CF}_{3} \mathrm{SO}_{3}\right)_{2}\right]^{2+}$ (right). 


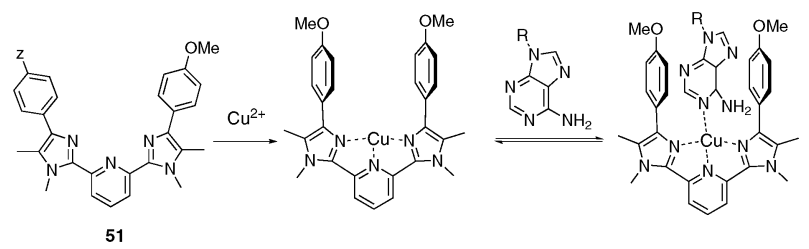

Fig. 44 Tweezer 51 and metal-assisted recognition of adenine.

and linear-pyridine metal-coordination. Different cleft entities are observed in both solution and solid state, and may be interconverted as a function of metal/ligand stoichiometry. In particular, robust self-complementary duplex cleft structures are generated with the pyridine side wall of one clip molecule filling the cavity of the other and vice versa, generating different zipper architectures.

Another example of a dynamic tweezer-type receptor triggered by metal coordination is proposed with compound 51 (Fig. 44). ${ }^{64}$ The metallo-tweezer is constructed in this case from a pyridine bisimidazole platform, bearing two appended anisole groups. In this tweezer-like complex, the copper atom organizes a binding pocket ideal for guest recognition with concomitant participation of the metal (coordination) and of the electron rich side walls. Intercalation of various aromatic heterocycles, including adenine $\left(K_{\mathrm{a}}=8.8 \times 10^{4} \mathrm{M}^{-1}\right.$, acetone $)$ or fluorescent dimethylaminostyrylpyridine $\left(K_{\mathrm{a}}=1.1 \times\right.$ $10^{5} \mathrm{M}^{-1}$ ) could be demonstrated.

Very recently, a series of new dynamic molecular tweezers whose recognition ability can be regulated by a metal-induced $\mathrm{W}$ to $\mathrm{U}$ switching has been described (e.g. compound 52) (Fig. 45). ${ }^{65,66}$ They differ from the previous electron-rich systems $\mathbf{4 7 - 4 9}$ by incorporating electron-poor NDI $(1,4,5,8$ naphthalenetetracarboxylic diimide) binding sites, prone to interact through $\pi$-stacking with electron-rich substrates. Such tweezer molecules have been, in particular, incorporated in dynamic libraries leading to functional constitutional dynamic networks. ${ }^{67}$ The metal coordinating subunit in this case corresponds to a pyridine-hydrazone-pyridine framework. Whereas free ligand $\mathbf{5 2}$ displays a $\mathrm{W}$-shaped conformation, the metal complex 52.M $(\mathrm{M}=\mathrm{Zn}, \mathrm{Hg}, \mathrm{Pb})$ presents a U-conformation, suitable for aromatic guests intercalation. The cavity size and shape are defined by the size of the metal cation, since a smaller cation should decrease the distance between both NDI walls, but also should lead to a severe pinching of the clip, preventing the insertion of a substrate. For instance, in the case of the $\mathrm{Pb}^{2+}$ complex, the addition of the electron-rich pyrene was accompanied with a colour change of the solution which turned from yellow to red with a $K_{\mathrm{a}}$ value of $320 \mathrm{M}^{-1}$

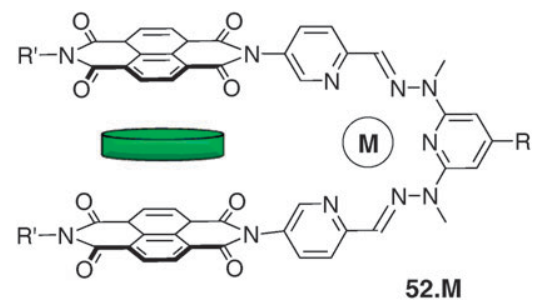

Fig. 45 Electron-poor tweezer 52.M molecule intercalating an electron-rich polyaromatic substrate.
$\left(\mathrm{CDCl}_{3} / \mathrm{CD}_{3} \mathrm{CN} 6: 4\right)$, whereas no binding was observed in the case of the smaller $\mathrm{Zn}^{2+}$ complex.

\section{Conclusion and outlook}

This tutorial review focuses on current trends in the design of molecular tweezers/clips through representative examples, and on their neutral guests binding properties. Such systems have known a growing interest in the last period, a consequence of new synthetic methodologies as well as a response to an increasing demand in the front of molecular machinery. Design optimization has been led on both the platform subunit, whose role is to control the spatial pre-organization and the rigid/flexible character of the system, as well as by varying the pair of binding units. Molecular tweezers presenting a distance of $c a$. $6.5-7 \AA$ between both binding arms obviously correspond to the most usual case appropriate for sandwiching aromatic planar guests. They generally support $\pi-\pi$ stacking interactions, which are eventually coupled to hydrogen bond or attractive $\mathrm{CH}-\pi$ interactions. Moreover, molecular electrostatic potentials have been shown recently to be powerful tools for the interpretation and the prediction of supramolecular interactions. On these grounds, the preferential binding and significant through-space interactions with the substituents can be rationalized based on computed electrostatic potentials of the clips and the guest molecules. ${ }^{68}$ Whereas most tweezers are electron-rich, new complementary examples appeared recently, involving electron-poor pincers, and exhibiting a good affinity for electron-rich guests. Recent efforts have also been produced in generating pincers programmed for receiving spherical guests like fullerenes, which is favored through concave-convex host-guest complementarity. New promising potentialities have appeared with dynamic molecular clips and tweezers that can change their conformations in response to external stimuli. Such controllable dynamic features can represent a new step towards "smart" adaptive nanodevices. Emergence of such systems is of strong potential interest in host-guest chemistry, chiral recognition ${ }^{28}$ but also for supramolecular catalysis and for the development of complex architectures that exhibit behaviours typically reserved for natural systems, paving the way to nanomechanical chemical systems and opening new research avenues in supramolecular chemistry. Finally, the development of molecular clips and tweezers soluble in water where the hydrophobic interactions govern the supramolecular phenomenon, are of particular interest to reach bioactive agents able to pinch biomolecules such as nucleobases, ${ }^{69}$ potential drug candidates,${ }^{70}$ or enzyme inhibitors. ${ }^{71,72}$

\section{Acknowledgements}

The authors gratefully acknowledge ANR-PNANO (TTF-Based Nanomat) for financial support.

\section{Notes and references}

1 J. W. Steed and J. L. Atwood, in Supramolecular Chemistry, John Wiley \& Sons Ltd, 2nd edn, 2009.

2 E. R. Kay, D. A. Leigh and F. Zerbetto, Angew. Chem., Int. Ed., 2007, 46, 72-191. 
3 Special Issue: Molecular Machines and Switches Adv. Funct. Mater. 2007, 17, 671-840.

4 C.-W. Chen and H. W. Whitlock Jr., J. Am. Chem. Soc., 1978, 100, 4921-4922.

5 S. C. Zimmerman, Top. Curr. Chem., 1993, 165, 71-102.

6 M. Harmata, Acc. Chem. Res., 2004, 37, 862-873.

7 F.-G. Klärner and B. Kahlert, Acc. Chem. Res., 2003, 36, 919-932.

8 S. C. Zimmerman, Bioorganic Chem. Frontiers, 1991, 2, 33-71.

9 R. P. Sijbesma and R. J. M. Nolte, Top. Curr. Chem., 1995, 175, 25-56.

10 A. E. Rowan, J. A. A. W. Elemans and R. J. M. Nolte, Acc. Chem. Res., 1999, 32, 995-1006.

11 E. M. Pérez and N. Martín, Pure Appl. Chem., 2010, 82, 523-533.

12 P. D. Harvey, C. Stern, C. P. Gros and R. Guilard, Coord. Chem. Rev., 2007, 251, 401-428.

13 R. P. Sijbesma, A. P. M. Kentgens, E. T. G. Lutz, J. H. van der Maas and R. J. M. Nolte, J. Am. Chem. Soc., 1993, 115, 8999-9005.

14 R. P. Sijbesma, S. S. Wijmenga and R. J. M. Nolte, J. Am. Chem. Soc., 1992, 114, 9807-9813.

15 J. N. H. Reek, J. A. A. W. Elemans and R. J. M. Nolte, J. Org. Chem., 1997, 62, 2234-2243.

16 P. Polavarapu, H. Melander, V. Langer, A. Gogoll and H. Grennberg, New J. Chem., 2008, 32, 643-651.

17 N. She, M. Gao, L. Cao, A. Wu and L. Isaacs, Org. Lett., 2009, 11, 2603-2606.

18 S. Ghosh, A. Wu, J. C. Fettinger, P. Y. Zavalij and L. Isaacs, J. Org. Chem., 2008, 73, 5915-5925.

19 P.-N. Chen, P.-T. Chiang and S.-H. Chiu, Chem. Commun., 2005, $1285-1287$.

20 P.-T. Chiang, P.-N. Chen, C.-F. Lin, Y.-H. Liu, C.-C. Lai, S.-M. Peng and S.-H. Chiu, Chem.-Eur. J., 2006, 12, 865-876.

21 K.-W. Cheng, C.-C. Lai, P.-T. Chiang and S.-H. Chiu, Chem. Commun., 2006, 2854-2856.

22 S. C. Zimmerman, C. M. VanZyl and G. S. Hamilton, J. Am. Chem. Soc., 1989, 111, 1373-1381.

23 S. C. Zimmerman and C. M. VanZyl, J. Am. Chem. Soc., 1987, 109, 7894-7896.

24 S. C. Zimmerman, M. Mrksich and M. Baloga, J. Am. Chem. Soc., 1989, 111, 8528-8530.

25 F.-G. Klärner, J. Panitzky, D. Bläser and R. Boese, Tetrahedron, 2001, 57, 3673-3687.

26 F.-G. Klärner, B. Kahlert, R. Boese, D. Bläser, A. Juris and F. Marchioni, Chem.-Eur. J., 2005, 11, 3363-3374.

27 F. Marchioni, A. Juris, M. Lobert, U. P. Seelbach, B. Kahlert and F.-G. Klärner, New J. Chem., 2005, 29, 780-784.

28 G. Fukuhara, S. Madenci, J. Polkowska, F. Bastkowski, F.-G. Klärner, Y. Origane, M. Kaneda, T. Mori, T. Wada and Y. Inoue, Chem.-Eur. J., 2007, 13, 2473-2479.

29 F.-G. Klärner, U. Burkert, M. Kamieth, R. Boese and J. Benet-Buchholz, Chem.-Eur. J., 1999, 5, 1700-1707.

30 F.-G. Klärner, B. Kahlert, A. Nellesen, J. Zienau, C. Ochsenfeld and T. Schrader, J. Am. Chem. Soc., 2006, 128, 4831-4841.

31 T. Han and C.-F. Chen, Org. Lett., 2006, 8, 1069-1072.

32 J. Cao, Y. Jiang, J.-M. Zhao and C.-F. Chen, Chem. Commun., 2009, 1987-1989.

33 J. Kagan, S.-A. Chen and D. A. Agdeppa Jr., Tetrahedron Lett., 1977, 18, 4469-4470.

34 M. Harmata and C. L. Barnes, J. Am. Chem. Soc., 1990, 112, $5655-5657$.

35 H. Kurebayashi, T. Mine, K. Harada, S. Usui, T. Okajima and Y. Fukazawa, Tetrahedron, 1998, 54, 13495-13504.

36 H. Kurebayashi, M. Sakaguchi, T. Okajima, T. Haino, S. Usui and Y. Fukazawa, Tetrahedron Lett., 1999, 40, 5545-5548.

37 M. Havlík, V. Král, R. Kaplánek and B. Dolenský, Org. Lett., 2008, 10, 4767-4769.

38 J. J. Turner and M. M. Harding, Supramol. Chem., 2005, 17, 369-375.
39 T. Kawase and H. Kurata, Chem. Rev., 2006, 106, 5250-5273.

40 A. Sygula, F. R. Fronczek, R. Sygula, P. W. Rabideau and M. M. Olmstead, J. Am. Chem. Soc., 2007, 129, 3842-3843.

41 L. Kobryn, W. P. Henry, F. R. Fronczek, R. Sygula and A. Sygula, Tetrahedron Lett., 2009, 50, 7124-7127.

42 B. Legouin, P. Uriac, S. Tomasi, L. Toupet, A. Bondon and P. van de Weghe, Org. Lett., 2009, 11, 745-748.

43 H. M. Colquhoun, Z. Zhu and D. J. Williams, Org. Lett., 2003, 5, 4353-4356.

44 H. M. Colquhoun and Z. Zhu, Angew. Chem., Int. Ed., 2004, 43, $5040-5045$.

45 B. G. Greenland, S. Burattini, W. Hayes and H. M. Colquhoun, Tetrahedron, 2008, 64, 8346-8354.

46 L. J. D'Souza and U. Maitra, J. Org. Chem., 1996, 61, 9494-9502.

47 D. Canevet, M. Sallé, G. Zhang, D. Zhang and D. Zhu, Chem. Commun., 2009, 2245-2269.

48 E. M. Pérez and N. Martín, Chem. Soc. Rev., 2008, 37, 1512-1519.

49 E. M. Pérez, L. Sánchez, G. Fernández and N. Martín, J. Am. Chem. Soc., 2006, 128, 7172-7173.

50 E. M. Pérez, A. L. Capodilupo, G. Fernández, L. Sánchez, P. M. Viruela, R. Viruela, E. Ortí, M. Bietti and N. Martín, Chem. Commun., 2008, 4567-4569.

51 G. Fernández, E. M. Pérez, L. Sánchez and N. Martín, Angew. Chem., Int. Ed., 2008, 47, 1094-1097.

52 M. A. Herranz, C. Ehli, S. Campidelli, M. Gutiérrez, G. L. Hug, K. Ohkubo, S. Fukuzumi, M. Prato, N. Martín and D. M. Guldi, J. Am. Chem. Soc., 2008, 130, 66-73.

53 C. Ehli, D. M. Guldi, M. A. Herranz, N. Martín, S. Campidellici and Maurizio Prato, J. Mater. Chem., 2008, 18, 1498-1503.

54 J.-Y. Balandier, M. Chas, P. I. Dron, S. Goeb, D. Canevet, A. Belyasmine, M. Allain and M. Sallé, J. Org. Chem., 2010, 75, 1589-1599.

55 T. Poulsen, K. A. Nielsen, A. D. Bond and J. O. Jeppesen, Org. Lett., 2007, 9, 5485-5488.

56 V. A. Azov, R. Gómez and J. Stelten, Tetrahedron, 2008, 64, 1909-1917.

57 M. Skibiński, R. Gómez, E. Lork and V. A. Azov, Tetrahedron, 2009, 65, 10348-10354.

58 H. Iwamoto, Y. Hidaka and Y. Fukazawa, Tetrahedron Lett., 2008, 49, 277-280.

59 K. A. Nielsen, W.-S. Cho, J. O. Jeppesen, V. M. Lynch, J. Becher and J. L. Sessler, J. Am. Chem. Soc., 2004, 126, 16296-16297.

60 K. A. Nielsen, W.-S. Cho, G. H. Sarova, B. M. Petersen, A. D. Bond, J. Becher, F. Jensen, D. M. Guldi, J. L. Sessler and J. O. Jeppesen, Angew. Chem., Int. Ed., 2006, 45, 6848-6853.

61 J. S. Park, F. Le Derf, C. M. Bejger, V. M. Lynch, J. L. Sessler, K. A. Nielsen, C. Johnsen and J. O. Jeppesen, Chem.-Eur. J., 2010, 16, 848-854.

62 A. Petitjean, R. G. Khoury, N. Kyritsakas and J.-M. Lehn, J. Am. Chem. Soc., 2004, 126, 6637-6647.

63 M. Barboiu, E. Petit and G. Vaugnan, Chem.-Eur. J., 2004, 10, 2263-2270.

64 J. P. Plante and T. E. Glass, Org. Lett., 2006, 8, 2163-2166.

65 S. Ulrich and J.-M. Lehn, Chem.-Eur. J., 2009, 15, 5640-5645.

66 S. Ulrich, A. Petitjean and J.-M. Lehn, Eur. J. Inorg. Chem., 2010, 13, 1913-1928.

67 J.-M. Lehn, Chem. Soc. Rev., 2007, 36, 151-160.

68 S. E. Wheeler and K. N. Houk, J. Chem. Theory Comput., 2009, 5, 2301-2312.

69 T. Schrader, Chem.-Eur. J., 1997, 3, 1537-1541.

70 S. T. Weiss, N. R. McIntyre, M. L. McLaughlin and D. J. Merkler, Drug Discovery Today, 2006, 11, 819-824.

71 P. Talbiersky, F. Bastkowski, F. G. Klarner and T. Schrader, J. Am. Chem. Soc., 2008, 130, 9824-9828.

72 M. Kirsch, P. Talbiersky, J. Polkowska, F. Bastkowski, T. Schaller, H. de Groot, F. G. Klarner and T. Schrader, Angew. Chem., Int. Ed., 2009, 48, 2886-2890. 